\title{
LA OCUPACIÓN SIMBÓLICA E IDEOLÓGICA DE WASHINGTON DURANTE LA ERA TRUMP: EL HUNDIMIENTO DE LA CAPITAL DE LOS ESTADOS UNIDOS EN LAS SERIES LA CONJURA CONTRA AMÉRICA, EL HOMBRE EN EL CASTILLOY EL CUENTO DE LA CRIADA
}

The Symbolic and Ideological Occupation of Washington during the Trump Era: The Collapse of the Capital of the United States in the Series The Plot Against America, The Man in the High Castle, and The Handmaid's Tale

Marco DA COSTA ${ }^{\mathrm{a}}$

Izmir University of Economics (Turquía) DOI: $10.15366 /$ secuencias2021.53.004

\begin{abstract}
RESUMEN
El acceso de Donald Trump a la presidencia de los Estados Unidos en 2016 generó multitud de corrientes de opinión a favor o en contra. En este último caso, se tradujo, entre otras manifestaciones, en el estreno de un grupo de producciones televisivas que reflexionaban críticamente sobre la historia de los Estados Unidos. En concreto, este artículo pretende mostrar cómo la ocupación del espacio público de la capital estadounidense, a partir de las distopías y ucronías televisivas de La conjura contra América, El cuento de la criada y El hombre en el castillo, se convirtió en un poderoso recurso metafórico para interpretar unos tiempos marcados por la crisis económica y el auge del populismo político.
\end{abstract}

Palabras clave: distopía, ucronía, La conjura contra América, El cuento de la criada, El hombre en el castillo, espacio público, Washington, D.C., series de televisión, nazismo.

\begin{abstract}
Donald Trump's accession to the presidency of the United States in 2016 generated a multitude of favorable and unfavorable currents of opinion. In the latter case, this translated, among other manifestations, into the creation of a group of television productions that critically reflected on the history of the United States. Specifically, this article aims to show how the occupation of the public space of the American capital, from the serial dystopias and uchronias of The Plot Against America, The Handmaid's Tale, and The Man in the High Castle, became a powerful metaphorical resource to interpret an era marked by the economic crisis and the rise of political populism.
\end{abstract}

Keywords: dystopia, uchrony, The Plot Against America, The Handmaid's Tale, The Man in the High Castle, public space, Washington, D.C., TV series, Nazism.

[a] Marco da Costa es profesor de lengua española y estudios culturales en la Izmir University of Economics (Turquía). Doctor en Filología Hispánica por la Universidad de Barcelona con mención de honor cum laude por su tesis La ideología nacionalsocialista a la luz de la intelectualidad fascista y contrarrevolucionaria española durante el Tercer Reich (1933-1945). Autor de numerosos artículos relacionados con el cine y los totalitarismos. Ha publicado, entre otros volúmenes, El cine japonés bajo el peso de la tradición: de Rashomon a The Ring (Editorial Azul, 2010), Ideología y propaganda en el cine del Tercer Reich (Editorial Comunicación Social, 2014), El cine del III Reich. Desmontando el cine nazi en 50 películas (Notorious Ediciones, 2016) y Hollywood contra Hitler (Notorious Ediciones, 2018). E-mail: marcodacosta1@hotmail.com 
El 10 de noviembre de 2016 medio mundo se levantaba conmocionado con la noticia de que Donald Trump, rompiendo todos los pronósticos de los sondeos iniciales, había ganado las elecciones al derrotar a la demócrata Hillary Clinton. El magnate se alzaba con la victoria gracias al apoyo masivo de una gran parte de la población descontenta con el establishment de la élite política norteamericana. Dos meses después, el 20 de enero de 2017, el cuadragésimo quinto presidente de la historia de los Estados Unidos juraba su cargo, como era habitual, en las escaleras del Capitolio.

Su discurso de toma de posesión compendiaba todo su ideario reaccionario, populista, negacionista, personalista, demagógico, nacionalista y proteccionista que le había llevado a la Casa Blanca ${ }^{1}$. Las viejas políticas que se habían beneficiado del pueblo, abandonándolo sin sus puestos de trabajo, dejaban paso a una nueva época en la que «el pueblo se convirtió, de nuevo, en el gobernante de la nación». Aquellas promesas de un futuro mejor, que retrotraían a ecos del pasado donde regímenes autoritarios y totalitarios, de todos los colores ideológicos, habían augurado nuevos amaneceres y nuevos órdenes después de la crisis bursátil de 1929, se limitaban a una autarquía económica y a un proteccionismo nacionalista de toda índole. Trump advertía que «durante décadas hemos enriquecido a la industria extranjera a expensas de la industria estadounidense [...]. Hemos gastado millones de dólares en el exterior mientras la infraestructura de los Estados Unidos ha decaído a un nivel terrible de destrucción». Había llegado el momento de pensar en reconstruir el país con «manos estadounidenses y mano de obra estadounidense». Sus planes para reducir el desempleo, que enlazaban, al mismo tiempo, con sus políticas antiinmigratorias, se completaban con dos simples reglas: «Buy American and Hire American». ${ }^{2}$

Todo el trasfondo ideológico que resonaría durante aquel desapacible y lluvioso día de enero frente al edificio que albergaba las dos cámaras del Congreso de los Estados Unidos quedaba, en definitiva, relegado a los deseos de Trump por anteponer los intereses del país por mediación de las consignas de su campaña electoral del America First y el Make America Great Again. El mesianismo caudillista de tiempos pretéritos se reflejaba en las palabras finales donde se comprometía, con la ayuda de todos, a «hacer a los Estados Unidos fuerte, de nuevo [...]; rico, de nuevo [...]; orgulloso, de nuevo [...]; seguro, de nuevo [...]; y sí, juntos haremos a Estados Unidos grandioso, de nuevo»s. ${ }^{3}$

La primera percepción que se detectaba de aquel discurso era que aquella «nueva visión» de gobernar la patria y aquel «movimiento histórico que el mundo no ha visto nunca» remitían, por el contrario, a ciertas páginas del populismo norteamericano como el «del presidente Andrew Jackson en el primer tercio del XIX, o el People's Party a finales de dicho siglo». ${ }^{4} \mathrm{Y}$ ese fue, de alguna manera, el sentimiento que predominaría y ha predominado en algunas series producidas después de la constitución de la nueva administración americana dirigida por Donald Trump. ${ }^{5}$ Se había pasado, pues, de aquellos productos — siempre dentro del género de la ciencia ficción — que proponían proyectos utópicos para salvar a la Tierra en términos morales, políticos y ecológicos (Star Trek: Deep Space Nine, Earth 2, Babylon 5, Terra Nova, etc.) ${ }^{6}$ a un grupo de producciones televisivas a las que se refería Javier Rueda en su artículo que generan un debate - a partir de la exposición de pasados alternativos en un país donde la propia administración Trump ha favorecido, desde la misma toma de posesión, los «hechos alternativos» (alternative facts) como versión distorsionada a la verdad cientí-
[1] Alfredo Ramírez Nárdiz, «Aproximación al pensamiento político de Donald Trump: ¿es el presidente de Estados Unidos populista?» (Revista Española de Ciencia Política, n. ${ }^{\circ}$ 52, 2020), pp. 61-67.

[2] «Compren productos americanos y contraten a americanos». Sin pretender hacer comparaciones entre dos mundos harto dispares, cabe decir que, durante el boicot contra las tiendas regentadas por propietarios judíos, el gobierno nazi, con la ayuda inestimable de las tropas de las SA, coaccionó a la población para que no comprara productos que no fueran alemanes con el eslogan: «Kauft nicht bei Juden!» («iNo compren a los judíos!»).

[3] El discurso completo de la toma de posesión de Donald Trump, con subtítulos en español, se puede visionar en YouTube. <https://www.youtube. com/watch? $\mathrm{v}=\mathrm{m} 9 \mathrm{tNsaOuVWo}>$ (23/01/2021).

[4] Alfredo Ramírez Nárdiz, «Aproximación al pensamiento político de Donald Trump: ¿es el presidente de Estados Unidos populista?», pp. 66-67.

[5] Javier Rueda, en «Reescrituras de la historia americana» (Caimán. Cuadernos de cine, n. $^{\circ}$ 92, abril de 2020), pp. 40-43, repasaba aquellas series televisivas que en los últimos años han reflexionado críticamente sobre la historia de los Estados Unidos como Homeland (Fox 21: 2011-2020), El hombre en el castillo (The Man in the High Castle, Amazon: 20152019), The Terror: Infamy (Scott Free: 2018), Watchmen (HBO: 2019), La conjura contra América (The Plot Against America, HBO: 2020) o Hunters (Amazon: 2020-).

[6] Concepción C. Cascajosa Virino, «Los turbios reflejos de la utopía en la ficción televisiva serial norteamericana» (Paradigma: revista universitaria de cultura, n. $\left.{ }^{\circ} 19,2016\right)$, pp. 30-33. 
[7] CNN, "Asesora de Trump: Casa Blanca citó "hechos alternativos" sobre asistencia a toma de posesión» ( $C N N, 22$ de enero de 2017). <https://cnn.it/2IJsLh3> (23/01/2021).

[8] Miquel Barceló, «Los temas de la ciencia ficción» (Revista de literatura, $\left.\mathrm{n}^{\circ}{ }^{\circ} 205,2004\right)$, pp. 57 66. <http://www.centrocp.com/ los-temas-de-la-ciencia-ficcion/ $>(23 / 01 / 2021)$

[9] Darko Suvin, «On the Poetics of the Science Fiction Genre» (College English, vol. 34, n. ${ }^{\circ} 3$, Dec. 1972), p. 372 y «Radical Rhapsody and Romantic Recoil in the Age of Anticipation: A Chapter in the History of SF» (Science Fiction Studies, vol. 1, n. ${ }^{\circ}$ 4, Fall 1974). <https://www.depauw.edu/ sfs/backissues/4/suvin4art.htm> (23/01/2021).

[10] Darko Suvin, Metamorfosis de la ciencia ficción. Sobre la poética y la historia de un género literario (Ciudad de México, Fondo de Cultura Económica, 1984), pp. 94 y 10, respectivamente. Las cursivas son añadidas. fica e intelectual ${ }^{7}$ - con un presente histórico enmarcado en una profunda crisis de las instituciones democráticas y en plena expansión de los populismos en todo el mundo $\mathrm{y}$, en concreto, de ciertos sectores de la ultraderecha más tradicionalista e integrista de la América profunda del Bible Belt y del WASP (white, anglo-saxon, protestant) que, aprovechando la ciclicidad de la historia, vuelven a imponer su ascendencia moral y a demandar un espacio político en la sociedad norteamericana.

En este diálogo ningún género ha sido tan proclive para tales fines como la ciencia ficción. Uno de sus usos como herramienta de análisis y crítica sociopolítica permite derivar las angustias, anhelos y curiosidades hacia un mundo futuro no vivido e imaginado en el que se intentará contestar a las preguntas de una humanidad huérfana de respuestas desde que Nietzsche proclamara la muerte de Dios. Como bien ha dicho Miquel Barceló,

este juego de imaginar futuros (utópicos o no) y, también, el advertir de los peligros implícitos en ciertas tendencias del presente, es uno de los aspectos más enriquecedores de la especulación propia de la ciencia ficción. En sentido opuesto, parte de la ciencia ficción, al revés de la prospectiva, a veces no pretende adivinar el futuro que será, sino conjurar algunos de los ominosos futuros que podrían aguardarnos. Intenta advertirnos que, de seguir por el camino que hemos emprendido, el futuro que nos aguarda puede resultar terrible. ${ }^{8}$

No es ninguna casualidad, por tanto, este repunte de la ciencia ficción durante el periodo en el que vivimos debido a los consustanciales cambios sociales, económicos y políticos que venimos asistiendo desde que empezó la crisis financiera en 2008. Ello no es, en todo caso, sino la constatación, por lo que se refiere a las series que nos atañen en este artículo y en su correlación con la irrupción inesperada en la palestra política de Donald Trump — que no implica necesariamente una relación causa-efecto-, de que tanto las distopías de sociedades futuras como las ucronías que reconstruyen $\mathrm{u}$ ofrecen sucesos alternativos a un pasado histórico son dos excelentes variantes del género de la ciencia ficción que permiten observar el mundo presente.

Uno de los principales y más influyentes teóricos del género como Darko Suvin basaba precisamente los orígenes genealógicos de la ciencia ficción en la creación de mundos alternativos («blessed islands», «fabulous voyage», «planetary novel», «utopia» and «anti-utopia», «state (political) novel», etc.) que aparecían en textos de la literatura grecolatina y en narraciones renacentistas y barrocas. ${ }^{9}$ En Metamorfosis de la ciencia ficción su autor profundizaría en los criterios para identificar a una obra de ciencia ficción y, para ello, desarrollaba su conocida poética del género definiéndolo como «literatura del extrañamiento cognitivo» en la que la ciencia ficción se caracterizaba «por el dominio o la hegemonía narrativa de un novum (novedad, innovación) validado mediante la lógica cognoscitiva» y que, a diferencia de la literatura fantástica, tanto sus personajes como los lugares en los que se situaba la acción resultaban «aceptados como no imposibles de acuerdo con las normas cognoscitivas (cosmológicas y antropológicas) de la época del autor». ${ }^{10}$

Así pues, detrás de aquella teoría de Suvin en la que se combinan la cognición del mundo empírico (ciencia, lógica y razón) con el extrañamiento y el novum (elementos ajenos pero basados en la propia realidad) se parapetan, de algún modo, la ucronía y la distopía de estas tres series: un extrañamiento anclado paradójicamente en un mundo completamente cognoscible para el espectador y que, al mismo tiempo, da sentido a 
sus mundos ficcionales. Por lo que atañe a uno de nuestros objetivos, los universos distópicos y ucrónicos representados en pantalla se ajustarían también a uno de los cuatro sistemas en los que el novum, según Carl D. Malmgren, debía manifestarse: el orden social («Social Order»). ${ }^{11}$ La inclusión de esta innovación se plantearía, para el caso, a partir de la hipótesis sobre qué habría pasado («What if?») si el mundo que conocemos se hubiera convertido en un Estado de carácter totalitario.

Estas preguntas, incertidumbres y planteamientos que cuestionan no tan solo el conocimiento empírico del mundo sino también las circunstancias presentes en las que vivimos suelen ser abordadas habitualmente bajo un amplio paraguas conceptual en el que términos interrelacionados entre sí, como utopía, distopía y ucronía se emplean, en ocasiones, de manera aleatoria a la hora de querer etiquetar un libro, una película o, incluso, una circunstancia coyuntural. Descartando la utopía al no ajustarse a la categorización de las series que analizaremos posteriormente, se puede definir la ucronía - El hombre en el castillo (The Man in the High Castle, Amazon: 20152019) y La conjura contra América (The Plot Against America, HBO: 2020)— como aquel subgénero hipotético (pero, sobre todo, verosímil) de la ciencia ficción en el que la aparición del novum trastoca la correlación diegética de los acontecimientos narrados en la historia o, en términos más generales, como un «relato basado en un supuesto cambio producido en la historia para producir una realidad alternativa»: ${ }^{12}$ en el caso de las dos series apuntadas, con la posibilidad contrafactual de una victoria de las potencias del Eje durante la Segunda Guerra Mundial. Por lo que se refiere a la distopía - El cuento de la criada (The Handmaid's Tale, Hulu: 2017-) -, concepto antagónico al mejor de los mundos posibles de la utopía, la novedad suviniana se enmarcaría dentro de un régimen despótico o de marchamo fundamentalista tal y como acontecía en la novela de Margaret Atwood.

Más allá de los fructíferos debates a la hora de sistematizar dichos conceptos, estos dos subgéneros cienciaficcionales (y sus consecuentes adaptaciones televisivas) nos interesan, en particular, por la ideologización intrínseca que conlleva su lectura y la vigencia que todavía detentan para calibrar la temperatura social, económica y cultural de nuestra sociedad. Desde la década de los setenta, y coincidiendo con los años de mayor fervor revolucionario (feminismo, ecologismo, antibelicismo, etc.), han sido muchos los críticos que se han ocupado de revelar la dimensión ideológica que se escondía detrás de aquel corpus cinematográfico englobado bajo la etiqueta genérica de la ciencia ficción. ${ }^{13} \mathrm{Si}$ nos adentramos propiamente en el terreno de la historia (re) creada y ficcionalizada de los Estados Unidos por estas tres series, Sobchack comentaba en su volumen sobre el género en el cine norteamericano que «las películas de ciencia ficción siempre están historiadas sobre la base de su (y nuestra) propia cultura norteamericana; en el presente económico, tecnológico, social y lingüístico de su producción, en las estructuras ideológicas que dan forma a sus concepciones visuales $\mathrm{y}$ visibles del tiempo, del espacio, del afecto y de las relaciones sociales». ${ }^{14}$

Sin voluntad de profundizar, dado que excede el espacio de este texto, en la literatura británica distópica (Brave New World; Nineteen Eighty-Four; A Clockwork Orange) y ucrónica (SS-GB: Nazi Occupied Britain 1941; Fatherland), ${ }^{15}$ estas tres series y las relaciones que establecen de hipertextualidad externa con sus respectivos materiales novelísticos en los que se basan, remiten, en nuestra opinión, a dos referentes del cine y la literatura norteamericana no tan invocados, como cabía esperarse, en comparación con los modelos canónicos anteriores. ${ }^{16}$ Tampoco es baladí hacer mención a que estos dos ejemplos aparecen durante la conflictiva década de los años
[11] Carl D. Malmgren, «Against Genre/Theory: The State of Science Fiction Criticism» (Poetics Today, vol. 12, n. ${ }^{\circ}$ 1, 1991), pp. 140-142. <https://scholarworks. uno.edu/cgi/viewcontent.cgi?article $=1048 \&$ context $=$ engl facpubs $>(23 / 01 / 2021)$.

[12] Fernando Ángel Moreno Serrano, Teoría de la literatura de ciencia ficción: Poética y retórica de lo prospectivo (Vitoria, Portal Ediciones, 2010), p. 462.

[13] Ofrecemos, a continuación, una breve muestra bibliográfica: Michael Stern, «Making Culture into Nature», en Alien Zone: Cultural Theory and Contemporary Science Fiction Cinema (London, Verso, 1990), pp. 66-72; Douglas Kellner y Michael Ryan, Camera Politica: The Politics and Ideology of Contemporary Hollywood Film (Bloomington, Indiana University Press, 1990), pp. 244265; Vivian Sobchack, Screening Space: The American Science Fiction Film (New Brunswick, Rutgers University Press, 19/97); Judith Hess Wright, "Genre Films and the Status Quo», en Film Genre Reader IV (Austin, University of Texas Press, 2012), pp. 60-68.

[14] Citado en J. P. Telotte, El cine de ciencia ficción (Madrid, Cambridge University Press, 2002), p. 54.

[15] Aparte de la translación a la gran pantalla de todas ellas, queremos destacar la adaptación televisiva en cinco episodios de la novela de Len Deighton, $S S-G B$ : Nazi Occupied Britain 1941 (Sid Gentle Films: 2017), que se estrenó en febrero de 2017, un mes después de la toma de posesión de Trump, conformando, junto a sus homólogas americanas ( $E l$ hombre en el castillo y La conjura contra América), la versión ucrónica de una Inglaterra bajo la ocupación nazi durante la Segunda Guerra Mundial. La serie está disponible en la plataforma online Filmin: <https://www.filmin.es/ serie/ss-gb?origin=searcher\&origin-type $=$ unique $>(23 / 01 / 2021)$. 
[16] Para un estudio de la hipertextualidad externa (cine, literatura, cómics, videojuegos, etc.) e interna (reutilización del propio material televisivo) en las series norteamericanas véanse los estudios de Concepción C. Cascajosa Virino, «Procesos de hipertextualidad en la ficción televisiva norteamericana» (Área abierta, n. ${ }^{\circ}$ 5, 2003), pp. 1-12 y «El espejo deformado: Una propuesta de análisis del reciclaje en la ficción audiovisual norteamericana» (Revista Latina de Comunicación Social, n. ${ }^{\circ}$ 61, 2006).

[17] La película se puede visionar también en Filmin: < https:// www.filmin.es/pelicula/el-despertar-de-una-nacion?origin $=-$ searcher\&origin-type $=$ unique $>$ (23/01/2021). Por otro lado, casualidades al margen, nada más conocerse los resultados de las elecciones americanas de 2016, Richard Spencer, padre del concepto alt-right que defiende el legado y la identidad de los americanos de origen europeo, declararía que la victoria de Trump sobre Clinton «ha sido un despertar»: véase $<$ https://elpais.com/internacional/2016/11/21/estados_unidos/1479765598 617726.html> (23/01/2021).

[18] Más información en Marco da Costa, Hollywood contra Hitler (Madrid, Notorious Ediciones, 2018), pp. 56-58.

[19] Este ha sido el caso de los gobiernos de China, Rusia, Moldavia, Israel, Serbia, Polonia, Turquía o Hungría que, parapetándose en la seguridad nacional para combatir el virus, han aprobado una serie de medidas de excepción que atentan, entre otros, contra la libertad de prensa, la oposición política o los derechos democráticos de todos los ciudadanos: véase $<$ https:/elpais.com/ internacional/2020-03-30/democracia-en-cuarentena-por-coronavirus.html> (23/01/2021). treinta (depresión económica, ascenso del NSDAP, invasión de Abisinia, masacre de Nankín, Guerra Civil española, etc.) con la que tantos paralelismos se han hecho con nuestra época a raíz de la recesión y el auge de la extrema derecha. En primer lugar se encuentra la película dirigida por Gregory La Cava, El despertar de una nación (Gabriel Over the White House, 1933). ${ }^{17}$ Estrenada el mismo mes de marzo en el que Hitler anulaba definitivamente el sistema parlamentario de Weimar, el film fantaseaba con unos Estados Unidos fascistas dirigidos por un presidente (interpretado por Walter Huston) que suspendía el Congreso y asumía la plena responsabilidad del gobierno decretando medidas populistas y pseudodictatoriales. ${ }^{18}$

El mensaje de aquella película, alertando de los peligros que se cernían sobre el pueblo americano si se priorizaba la solución del paro, de la anarquía social y de las penurias económicas — léase también pandemia del coronavirus ${ }^{19}$ — por encima de la libertad y los derechos civiles, se radicalizaba en la novela Eso no puede pasar aquí (It Can't Happen Here, 1935) de Sinclair Lewis. ${ }^{20}$ El primer americano que recibiría el Premio Nobel de Literatura abordaba las consecuencias de unos Estados Unidos bajo las garras del fascismo centrándose en las desventuras de un honrado periodista de un pequeño pueblo de Vermont que presenciaba horrorizado la victoria en las elecciones generales del senador populista «Buzz» Windrip. A partir de aquel momento, la pesadilla se convertía en un Estado dirigido por este nuevo dictador y su camaradería de gerifaltes que emularía descaradamente al nacionalsocialismo de la época: aniquilación del sistema de partidos, tropas de asalto denominadas «Minute Men», prohibición y quema de libros, campos de concentración, uso legal de la tortura, políticas antiinmigración, discursos antisemitas, ansias expansionistas concentradas sobre territorio mexicano, etc. Como contrapartida, Lewis describía la existencia de un movimiento de resistencia que, además de minar las estructuras de aquel gobierno totalitario, «ayudaba a miles de contrarrevolucionarios a escapar a Canadá». ${ }^{21}$

Así pues, estas dos referencias marcaron el camino para todas aquellas distopías y ucronías americanas que vendrían posteriormente al plantearse, de alguna manera, la misma pregunta que aparecía en la portada de la primera edición de Eso no puede pasar aqui: «What will happen when America has a dictator?».22 Después de la subida de Trump al poder y a medida que se iban estrenando El cuento de la criada (26 de abril de 2017) o La conjura contra América (16 de marzo de 2020), el debate en prensa entre los críticos televisivos se enfrascó en si aquellas series interpretaban

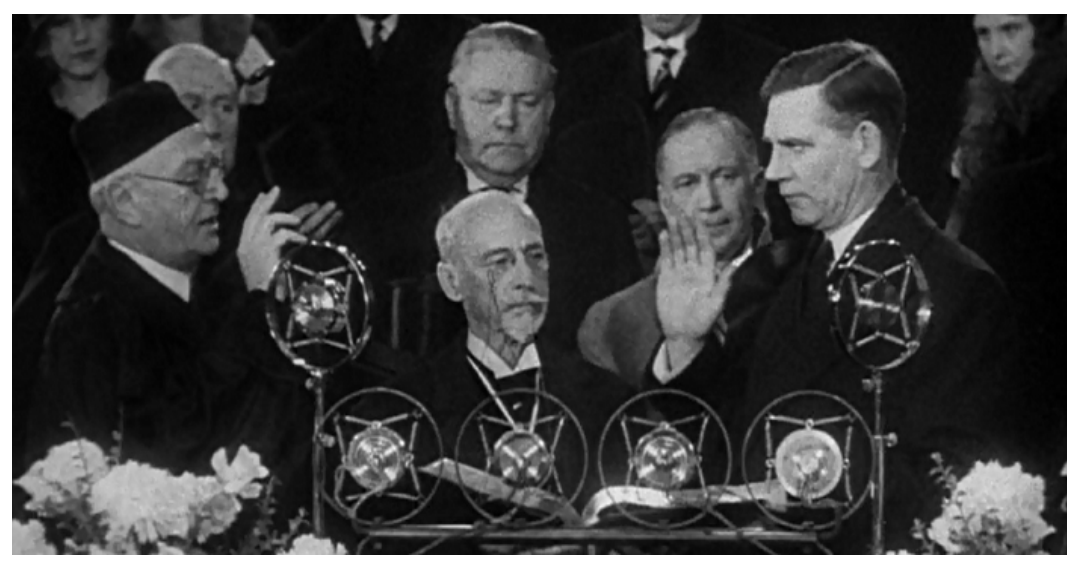

Walter Huston en El despertar de una nación (Gabriel Over the White House, Gregory La Cava, 1933). 
alegóricamente, o no, el espíritu de los tiempos tal y como lo habían hecho en los años treinta las obras de Gregory La Cava y Sinclair Lewis. ${ }^{23}$ Incluso la serie que llevaría a la pequeña pantalla la novela de Philip K. Dick, El hombre en el castillo, si bien se estrenaba en enero de 2015, no ha dejado de analizarse como resultado del periodo post-9/11, tras los ataques terroristas en Nueva York, o como un producto de la era de la posverdad donde predomina el discurso retórico y estratégico de políticos como Trump basado en la difusión de bulos y mentiras, en teorías de la conspiración y en la exaltación de las emociones por encima de principios racionalistas. ${ }^{24}$

\section{La ocupación de la capitalidad totalitaria (Germania) como antecedente histórico del Washington distópico-ucrónico}

Terminado este primer punto contextualizador, resulta necesario adentrarse en la importancia que otorgaron los regímenes totalitarios a la ocupación del espacio público como medida represora y de control ideológico sobre la población para, acto seguido, en el último apartado, delimitar el cambio fisionómico-urbanístico experimentado por Washington en las tres series analizadas a lo largo de su particular proceso ficcional: una involución que llevaría a la propia capital y, por extensión, a todos los Estados Unidos a la desdemocratización, a saber, la «pérdida del contenido democrático» con la consecuente ruptura de las relaciones entre el Estado y la ciudadanía en cuanto al libre ejercicio de derechos civiles, consultas "vinculantes, amplias, iguales y protegidas", la libertad de expresión y de la independencia judicial, etc. ${ }^{25}$.

Para este artículo, nos interesa el análisis de la ucronía y la distopía en El hombre en el castillo (The Man in the High Castle, Amazon Studios: 2015-2019), El cuento de la criada (The Handmaid's Tale, Hulu: 2017-) y La conjura contra América (The Plot Against America, HBO: 2020) no tanto por su ruptura del timeline como por el simple hecho de que esa misma reconstrucción alternativa o paralela de la historia pueda alterar las señas identitarias de una ciudad y, por lo tanto, de la propia sociedad. En el caso de los Estados Unidos y si nos enfocamos en la geografía que aparecía en estas series, ciudades como San Francisco, Nueva York o Washington ya no eran las ciudades a las que estábamos acostumbrados: se habían convertido en «iconos de la dominación colonial» en cuyos edificios y espacios públicos predominaban los símbolos y referentes culturales, sociales y propagandísticos impuestos a la sociedad norteamericana por los nuevos dueños. ${ }^{26}$

Por todo ello, comenzaremos por aludir al concepto de espacio público que Hannah Arendt definía como una esfera de principios igualitarios en la que un grupo de ciudadanos heterogéneos se escuchaban sin entrar en conflicto los unos con los otros. ${ }^{27} \mathrm{El}$ problema radicaba, continuaba la filósofa alemana, cuando este aspecto libre del foro se perdía ante la intervención de un gobierno autoritario o dictatorial. ${ }^{28}$ En lo tocante a nuestro objetivo, esta intromisión en el espacio público tiene en la trágica historia del siglo XX una serie de modelos políticos en los que el urbanismo y la arquitectura se pusieron al servicio de regímenes estatalistas con el claro objetivo de imponer un credo ideológico, organizar la vida social y reprimir cualquier conato de disidencia. Como comprobaremos con la capitalidad de Washington exhibida en las series, esta estetización de la política — en términos benjaminianos y como expresión fehaciente del poder alcanzado por el gobierno de ocupación germano-japonés (El hombre en el castillo), el gobierno teocrático de la República de Gilead (El cuento de la criada) y el gobierno fascista de Charles Lindbergh (La conjura contra América) - tuvo en la
[20] Solo por un desconocimiento de la novela de Sinclair Lewis se puede entender que fuera el 1984 orwelliano el que se convirtiera en un superventas después de la llegada de Trump a la Casa Blanca: véase $<$ https://elpais. com/cultura/2017/01/26/actualidad/1485423697_413624.html> (23/01/2021). Daniel Burston en su artículo, «It Can't Happen Here: Trump, Authoritarianism and American Politics») (Psychotherapy and Politics International, $\mathrm{n}^{\circ}$ 205, 2017), pp. 1-9, hace un repaso, desde la década de los treinta, del concepto del «autoritarismo» mientras juega irónicamente con el título de la novela de Sinclair Lewis y la irrupción política del trumpismo en los Estados Unidos.

[21] Sinclair Lewis, Eso no puede pasar aquí (Madrid, A. Machado Libros, edición para Kindle, 2012), loc. 2773. Canadá, a la que se definiría casi al final como el país donde «los estadounidenses tenían su Muro de las Lamentaciones» (loc. 6075), aparecía en It Can't Happen Here tal y como lo han recogido simbólicamente las series basadas en las novelas de Philip Roth (La conjura contra América) y de Margaret Atwood (El cuento de la criada), tanto en su condición de paraíso de las libertades democráticas y refugio para escapar de gobiernos teocráticos o antisemitas como también en su faceta ejemplar de lucha contra el fascismo en Europa durante la Segunda Guerra Mundial.

[22] «¿Qué ocurrirá cuando América tenga un dictador?» (La traducción es nuestra).

[23] Sarah Jones llegaba a comparar Texas e Indiana con Gilead: véase $<$ https://newrepublic.com/ article/141674/handmaids-tale-hulu-warning-conservative-women> (23/01/2021). Por su parte, Rebeca Mead, <https://www.newyorker. com/magazine/2017/04/17/margaret-atwood-the-prophet-of-dystopia $>(23 / 01 / 2021)$, observaba paralelismos entre el gobierno de Trump y la República de Gilead aunque reconocía que «El Presidente Trump no es partidario de los valores tradicionales familiares; se ha divorciado muchas veces. No se le conoce que sea un hombre con fuertes principios religiosos; sus domingos los suele pasar en el campo de 
golf» (la traducción es nuestra). Por el contrario, los artículos de Jessa Crispin, $<$ https://www.theguardian. com/commentisfree/2017/may/02/ handmaids-tale-donald-trump-america $>(23 / 01 / 2021)$, y de Barbara Kay, <https://nationalpost.com/ opinion/barbara-kay-the-problemwith-handmaids-tale-is-that-itsnot-a-believable-dystopia-its-scifi> (23/01/2021), evitaban recurrir a cualquier similitud dado que Trump había sido elegido en las urnas y no existía en la sociedad americana ni en ningún país democrático del mundo un programa ideológico-religioso como el de Gilead. En el caso de la miniserie de $\mathrm{HBO}$, su creador y productor, David Simon, no rehuía en ningún momento la vinculación de la deriva imaginaria de los Estados Unidos hacia el fascismo con el estilo mesiánico de Donald Trump mientras, en una entrevista, opinaba que «estoy convencido de que [...] estamos en una trayectoria que nos lleva a un giro hacia el autoritarismo, si no tomamos conciencia de nuestra vulnerabilidad y de la debilidad de la democracia»: véase $<$ https://www.revistaarcadia. com/television/argticulo/la-conjura-contra-america-de-hbo-paralelismo-audaz-con-el-ascenso-de-trump/81171> (23/01/2021). De la misma manera, el artículo de Majid Shirvani, «Deconstructing Roth's The Plot Against America: The Making of the President Donald Trump», en Rethinking Social Action. Core Values in Practice (Suceava, Lumen Proceedings, 2017), pp. 808-819, se centra en la comparativa personal y profesional entre el Lindbergh-presidente de la novela y el Trump-presidente electo en noviembre de 2016.

[24] Moritz Fink, «Why America Fought: Post-Postmodernism in Amazon's The Man in the High Castle» (SPIEL: Journal of Media Culture, vol. 2, n. ${ }^{\circ}$ 2, 2016), p. 144; Kevin Fallon, «The Man in the High Castle: Creator Frank Spotnitz on Making Amazon's Hit Drama» (Daily Beast, 27 de noviembre de 2015). <https://www. thedailybeast.com/the-man-inthe-high-castle-creator-frankspotnitz-on-making-amazonshit-drama> (23/01/2021); Timucin Edman, Hacer Gözen y Davut Peaci, «The Man in the High Castle: An Awry Reality Through Post-Truth» (Interactions, vol. 29, n. $\left.{ }^{\circ} 1-2,2020\right)$, pp. 77-100.
Germania ideada por Hitler y su arquitecto favorito, Albert Speer, su máxima expresión. ${ }^{29}$

El dictador alemán, desde su juventud, había quedado impresionado por la antigüedad grecolatina así como por el neoclasicismo que florecería en el siglo XIX. ${ }^{30} \mathrm{El}$ arte, en su opinión, y especialmente la arquitectura, debía ser bello, natural y útil para la fortaleza de la comunidad nacional. A estas cualidades se le añadía el componente de eternidad-colosalismo necesario para que el Tercer Reich de los Mil Años se hiciera inmortal en los siglos venideros. Emulando el uso de la piedra y el granito que habían asegurado la pervivencia de los vestigios arquitectónicos del pasado, Hitler ordenó construir la mayoría de los edificios de la nueva arquitectura nacionalsocialista bajo la «teoría del valor de las ruinas» (Ruinenwerttheorie) que, al igual que las Pirámides, el Partenón, el Coliseo y las catedrales del Medievo, daría testimonio del paso imperecedero del nazismo por la historia. ${ }^{31}$

Este proyecto de remodelación urbanística, en el que se impondría un estilo ecléctico entre el neoclasicismo, el monumentalismo y el ruralismo autóctono, se extendería a lo largo y ancho del territorio geográfico de la Alemania nazi. ${ }^{32}$ Sin embargo, el proyecto estrella de Hitler con Speer fue la destrucción de grandes extensiones del Berlín weimariano y la (re)definición del concepto de capitalidad política e ideológica que adquiriría la nueva capital del Reich a partir de su bautismo con el nombre de Germania. ${ }^{33}$ Para ello se diseñó un ambicioso plan que albergaba, entre otros, la construcción de una Gran Avenida de siete kilómetros que cruzaría de Norte a Sur la capital, jalonada por edificios ministeriales, cines, teatros, hoteles, restaurantes, etc. En cada extremo de aquel Eje destacarían por su monumentalidad la Gran Sala (Große Halle) con una cúpula de 290 metros de altura y capacidad para 200.000 asientos y un Arco de Triunfo que empequeñecería a su homólogo parisino. ${ }^{34}$

El avance de la tecnología y los efectos especiales en el cine permitieron que las maquetas de Speer y los sueños faraónicos de Adolf Hitler se hicieran realidad en la adaptación televisiva de El hombre en el castillo. ${ }^{35}$ En concreto, el último episodio de la primera temporada («A Way Out») ofrecía una extraordinaria panorámica de la Gran Avenida cruzando lo que hoy es el Tiergarten y, al fondo, la majestuosa cúpula de la Gran Sala dominando el skyline berlinés.

En el último episodio de la segunda temporada («Fallout») la serie volvía al Berlín nazi de los años sesenta y accedía al interior de la Große Halle diseñada por Speer donde Heinrich Himmler se dirigía a todo el pueblo alemán para justificar una nueva «Noche de los cuchillos largos»y convertirse en el nuevo Führer.

Aquella Germania nazi, victoriosa en la Segunda Guerra Mundial gracias a la ucronía de Philip K. Dick, no se habría alejado en demasía del significado simbólico que atesora hoy en día - lógicamente en el plano

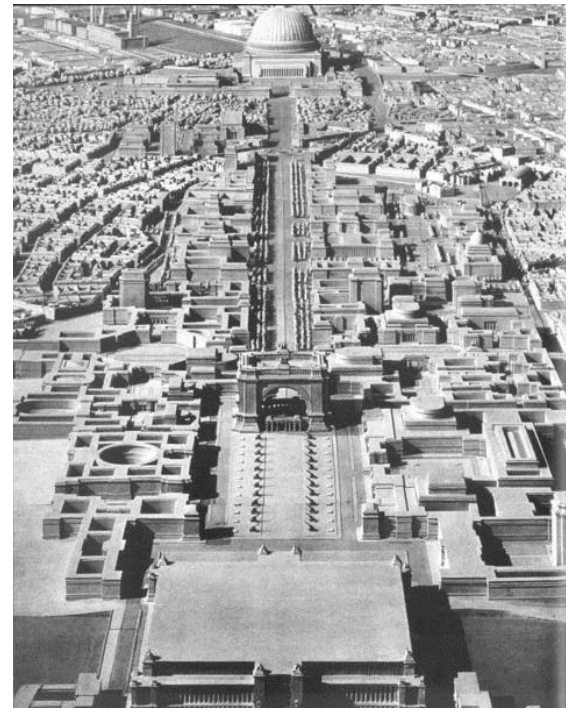

Maqueta de Albert Speer para el proyecto «Germania». 

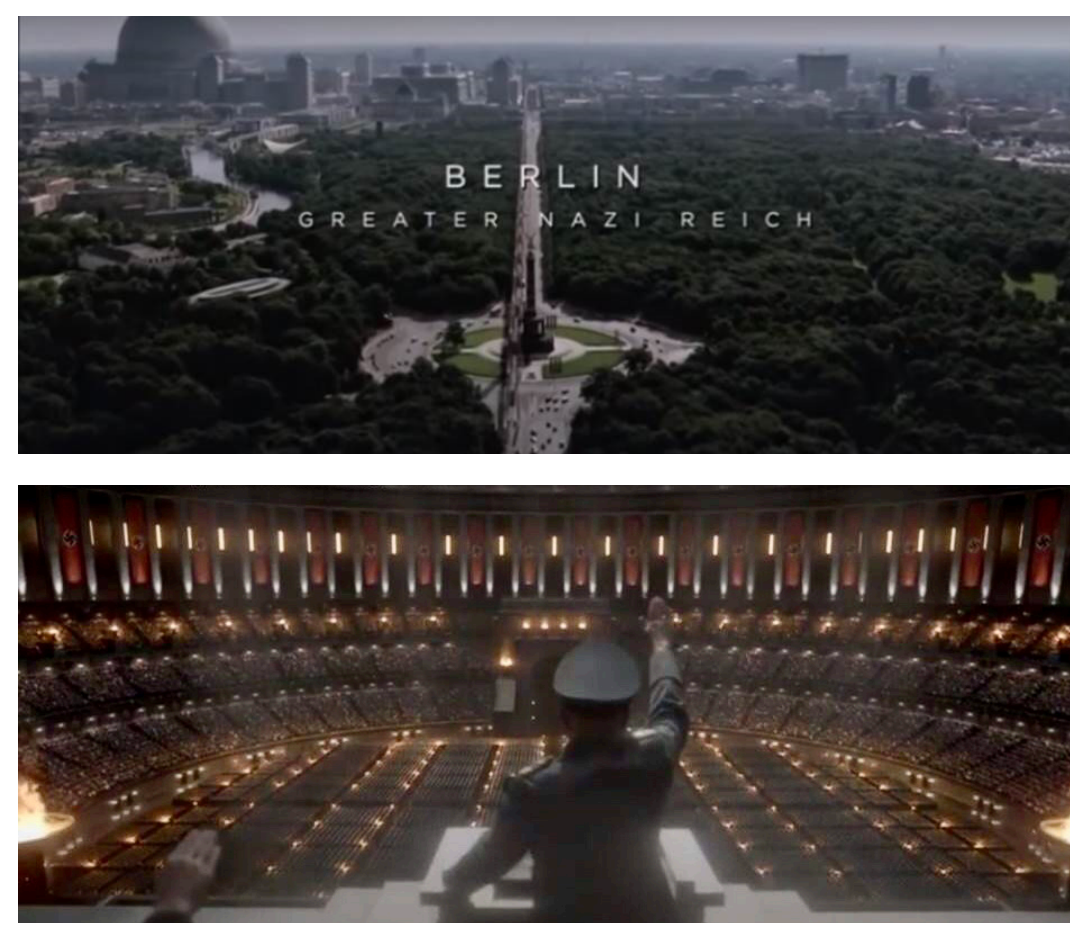

Arriba, vista aérea de Germania con la cúpula de la Gran Sala al fondo. Fotograma del episodio 10 ("A Way Out») de la primera temporada de El hombre en el castillo. Abajo, Himmler dirigiéndose al pueblo alemán en el interior de la Gran Sala. Fotograma del episodio 10 («Fallout») de la segunda temporada de El hombre en el castillo.

opuesto en cuanto a cosmovisión ideológica - la capital de los Estados Unidos. Cuando se visita Washington, D.C., y, en particular, el Capitolio como uno de sus iconos por antonomasia, se tiene la impresión de estar en el «corazón mismo de la historia norteamericana». ${ }^{36} \mathrm{Y}$ es que aquella ciudad se desarrollaría con el único propósito de convertirse en sede del gobierno nacional, construyéndose a su alrededor, a finales del siglo XVIII, varios edificios de estilo neoclásico que todavía se pueden contemplar hoy. Será a partir de 1945 con la victoria de los Aliados sobre el fascismo cuando la capital y, sobre todo, la famosa Explanada Nacional (National Mall), localizada en el mismo centro histórico, adquieran no solo relevancia turística a nivel internacional sino que, a través del cine americano de la posguerra, impongan en el imaginario colectivo su impronta simbólica, ideológica y, por qué no decirlo también, propagandística de la posición dominante de los Estados Unidos en el mundo cuya ascendencia, en todos los sentidos, llega hasta nuestros días.

En el National Mall se congregan, por tanto, una gran cantidad de ministerios, monumentos, museos (Museo del Holocausto, Museo Nacional de Historia Americana, Museo Nacional de Arte Americano, etc.) y memoriales dedicados a los veteranos de la Segunda Guerra Mundial, Corea y Vietnam y a figuras tan destacadas de su historia como Thomas Jefferson, Ulysses S. Grant, Franklin D. Roosevelt y Martin Luther King: conformando, todo ello, un enorme espacio público identitario donde el ciudadano norteamericano pueda identificarse y reconocerse en los ideales democráticos de los Padres de la Constitución y con la breve historia de su país.

No cabe duda de que los cuatro monumentos más icónicos de este lugar de culto
[25] Nos apropiamos, para el caso, del término desdemocratización, acuñado por el sociólogo estadounidense, Charles Tilly, como reflejo del riesgo a que las instituciones democráticas y los valores que representan se deterioren ante los desafíos planteados desde la llegada de la crisis económica en el 2008: Charles Tilly, Democracia (Madrid, Akal, 2010), pp. 31-56 y 85-101.

[26] Nelson Arteaga, «La historia como realidad y ficción: los distintos mundos de El hombre en el castillo» (Norteamérica, vol. 13, n. $\left.{ }^{\circ} 2,2018\right)$, p. 308.

[27] Hannah Arendt, La condición humana (Barcelona, Paidós, 1998), p. 62.

[28] Un excelente estudio crítico de cómo, incluso, las instituciones democráticas se sirven del espacio público para disciplinar cívica y moralmente a sus ciudadanos se encuentra en Manuel Delgado, El espacio público como ideología (Madrid, Catarata, 2011), pp. $15-40$.

[29] Recomendamos la lectura del artículo de Zira Box, «El cuerpo de la nación. Arquitectura, urbanismo y capitalidad en el primer franquismo» (Revista de Estudios Políticos, n. $\left.{ }^{\circ} 155,2012\right)$, pp. 151181 , en relación con los planes urbanísticos y diseños arquitectónicos del primer franquismo para desterrar el liberalismo urbano de Madrid y convertirla en la capital imperial del Nuevo Estado falangista.

[30] Uno de los objetivos del artículo de Miguel Abensour, «De la compacidad» (Revista de Estudios Sociales, n. ${ }^{\circ} 35$, abril de 2010), es precisamente «salvar la arquitectura neoclásica, disociándola del nacionalsocialismo» e intentar negar la relación entre los regímenes totalitarios y un estilo arquitectónico. $<$ https://journals.openedition.org/ revestudsoc/14603> (23/01/2021).

[31] Albert Speer, Memorias (Barcelona, Acantilado, 2001), pp. 102-106. 
[32] Sobre el arte y la arquitectura urbana bajo el nacionalsocialismo se han consultado: Peter Adam, $E l$ arte del Tercer Reich (Barcelona, Tusquets, 1992); Johann Chapoutot, El nacionalsocialismo y la antigüedad (Madrid, Abada Editores, 2013), pp. 321-360; Maik Kopleck, Munich, 1933-1945 (Berlín, Ch.Links, 2006); Maik Kopleck, Obersalzberg, 19331945 (Berlín, Ch.Links, 2007); Éric Michaud, La estética nazi. Un arte de la eternidad (Buenos Aires, AH, 2009); Alexander Schmidt y Markus Urban, Terreno de las convenciones del Partido del Reich en Núremberg (Nuremberg, Geschichte Für Alle, 2007).

[33] «Quizá convendría, para apoyar esta trayectoria, cambiar el nombre de Berlín y llamar Germania a la capital del Reich, puesto que este nombre permitiría, en su nuevo significado, que la capital del Reich fuese el centro de la raza aria, sea cual fuere la distancia que separa de ella a sus diversos miembros»: Hugh Trevor-Roper (ed.), Las conversaciones privadas de Hitler (Barcelona, Crítica, 2004), p. 418.

[34] Más información sobre Germania en Maik Kopleck, Berlin, 1933-1945 (Berlín, Ch.Links, 2005), pp. 29-37 y Rosa Sala Rose, Diccionario crítico de mitos y símbolos del nazismo (Barcelona, Acantilado, 2003), pp. 159-167.

[35] A nivel literario, la Germania de Hitler y Speer aparecía materializada en la novela ucrónica de Robert Harris, Patria (Barcelona, Random House, edición para Kindle, 2011), loc. 395 y ss.

[36] Philip Roth, La conjura contra América (Barcelona, Random House, edición para Kindle, 2011), loc. 1031

[37] Philip Roth, La conjura contra América, loc. 3354 y 3362. Recordemos que en el libro de Roth el presidente de los Estados Unidos es el filonazi y antisemita Charles Lindbergh.

[38] Philip Roth, La conjura contra América, loc. 988. por y para la democracia americana son la Casa Blanca, el Capitolio, el Memorial a Lincoln y el Monumento a Washington, famoso obelisco tantas veces fotografiado en las aguas del Reflecting Pool. No será, pues, ninguna coincidencia que sean estos edificios emblemáticos de la dominación colonial americana los que aparezcan retratados en unas series cuyos argumentos principales se centran en la subversión del sistema democrático del país o en la reinterpretación ucrónica de la historia. En todo caso, llama la atención, por el contrario, que no surja en ningún capítulo televisivo la residencia oficial del presidente de los Estados Unidos. Aunque quizás la respuesta la obtengamos a partir del comentario que le lanzaba Herman — padre del narrador en las memorias ficcionales de Philip Roth - a su cuñada cuando esta le ofrecía a su sobrino una invitación de la Casa Blanca para honrar la visita del ministro de Asuntos Exteriores nazi, Joachim von Ribbentrop: «iNo me impresiona la Casa Blanca! [...]. Solo me impresiona quién vive allí. Y la persona que vive allí es un nazi». ${ }^{37}$

\section{Destrucción y deconstrucción de Washington, D.C.}

Antes de abordar la representación de Washington a través de tres episodios pertenecientes a El hombre en el castillo, El cuento de la criada y La conjura contra América conviene tener en cuenta dos puntualizaciones: la primera, que el estreno de dichos episodios se produjo en el último bienio de la administración Trump, entre junio de 2019 y marzo de 2020; la segunda tiene que ver con el orden de aparición de las series en este último apartado. Este no se ceñirá a los parámetros cronológicos de emisión en televisión o plataformas VOD sino que se ajustará a la propia evolución-transformación de la capital de los Estados Unidos, desde la fascistización política del gobierno de la nación (La conjura contra América), transitando por la destrucción de todos aquellos monumentos y edificios representativos de los ideales democráticos (El hombre en el castillo), hasta su definitiva conversión ideológica a través de la usurpación del espacio público (El cuento de la criada).

Debido al criterio seleccionado, iniciaremos este particular recorrido por el Washington ucrónico con el episodio tercero de La conjura contra América en el que tenía lugar el simbólico viaje de los Levin a la capital. En la novela de Philip Roth se explicaba que el matrimonio había estado ahorrando casi dos años para realizar aquella visita soñada. La subida al poder de Charles Lindbergh en noviembre de 1940, y a pesar de las reticencias y miedos de su mujer que comienza a plantearse la opción de huir a Canadá, no impedía viajar a Herman, seis meses después, con su familia al completo, desde Nueva York a Washington, con el firme propósito de comprobar, in situ, que «Estados Unidos no era un país fascista y no lo sería». ${ }^{38}$

La secuencia cinematográfica de la visita adquiría un significado de camino sin retorno para una familia judía en la que la mujer, Bess, le había dicho a Herman poco antes de partir hacia la capital que «quizás es demasiado pronto para marchar pero no es demasiado pronto para tener un plan». El viaje se convertía, en este sentido, y en especial para Herman, admirador de las políticas del New Deal de Roosevelt y fiel representante del judaísmo de izquierdas, en un periplo metafórico en busca de la reafirmación de unos valores y de un credo político que el nuevo gobierno de Lindbergh, pactando con Hitler o eligiendo al antisemita Henry Ford como secretario de Estado, estaba poniendo en peligro. ${ }^{39}$ Además, tal y como habían ejecutado los nazis a partir de las Leyes de Núremberg, Herman y el resto de la comunidad judía sentían que, de la noche a la mañana, se les había despojado de su americanidad y de su condición de 


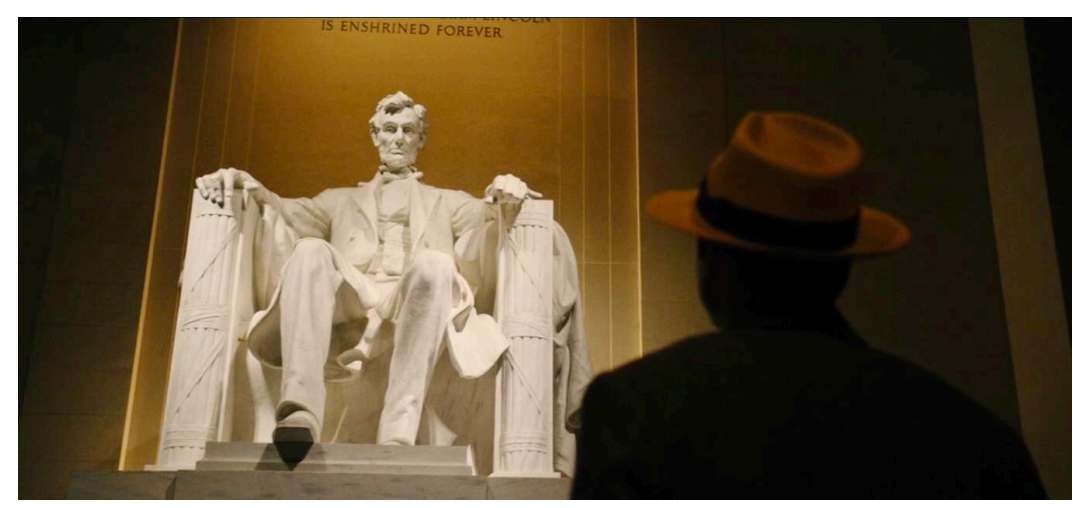

Herman Levin ante la estatua de Abraham Lincoln. Fotograma del episodio 3 de La conjura contra América.

ciudadanos de primera con plenos derechos para, a la postre, etiquetarlos dentro de una ortodoxia religiosa a la que muchos de sus antepasados europeos habían renunciado y abandonado al emigrar al paraíso americano.

Toda esta crisis identitaria ideológica — más que religiosa o espiritual— se confrontaba precisamente durante el paseo nocturno que daba la familia, con la ayuda de un guía turístico local, a lo largo del famoso estanque. Tras haber subido al obelisco sobre el cual Herman informaba que había sido restaurado bajo la administración de Roosevelt, se dirigían al Memorial a Lincoln donde, al pie mismo de las escaleras, Herman tendría el primer golpe de realidad con una pareja de seguidores del presidente que le insultaba tildándolo de «judío bocazas» (loudmouth Jew). ${ }^{40}$ Aun así, la entrada al monumento le hacía olvidar el altercado anterior cargado de un antisemitismo galopante. La extasiada contemplación del personaje frente a la famosa estatua reproducía, de algún modo, las palabras que sentía su hijo pequeño al definir, en la novela, «su rostro esculpido» como «la amalgama más sagrada posible, el rostro de Dios y el de América en uno solo». ${ }^{41}$

La segunda parada obligatoria dentro del sancta sanctorum dedicado al presidente Lincoln era el «Discurso de Gettysburg» que había pronunciado el 19 de noviembre de 1863 en el Cementerio Nacional a raíz de la famosa batalla acontecida durante la Guerra Civil americana. Grabadas sus 272 palabras en la pared sur de una de las salas laterales, Herman obligaba a su hijo pequeño, Phillip, a leer el discurso sintiendo la necesidad de pronunciar en voz alta alguna de sus sentencias, «All men are created

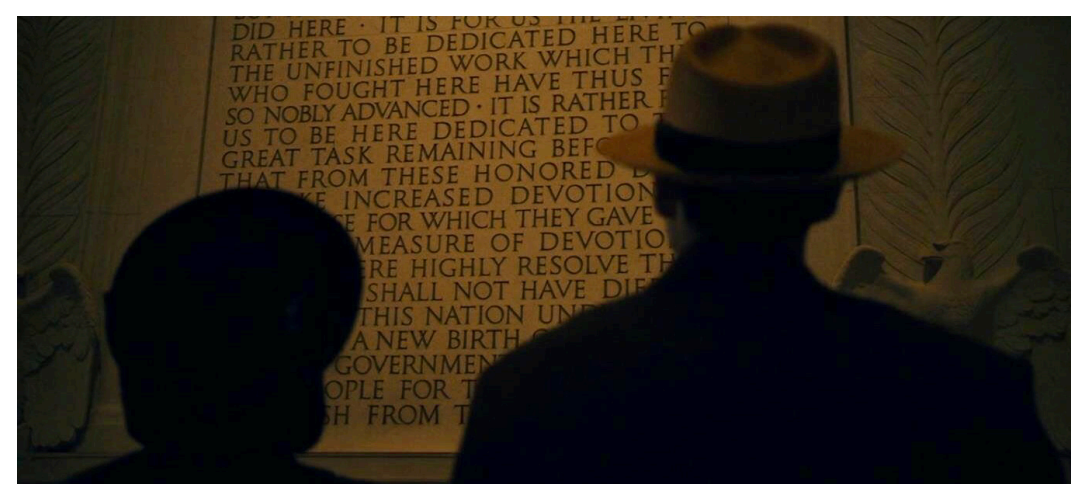

Lectura del «Discurso de Gettysburg». Fotograma del episodio 3 de La conjura contra América.
[39] Gurumurthy Neelakantan, «Philip Roth's Nostalgia for the Yiddishkayt and the New Deal Idealisms in The Plot Against America» (Philip Roth Studies, vol. 4, n. $\left.^{\circ} 2,2008\right)$, p. 126 y Christopher Vials, «What Can Happen Here?: Philip Roth, Sinclair Lewis, and the Lessons of Fascism in the American Liberal Imagination» (Philip Roth Studies, vol. 7, n. $\left.{ }^{\circ} 1,2011\right)$, pp. 20-23.

[40] Bess, en un momento dado, le comenta a su marido que está hablando demasiado delante de un guía turístico al que no conocen. Herman le contesta, convencido, que «no estamos en Berlín».

[41] Philip Roth, La conjura contra América, loc. 1139. 
[42] E1 discurso completo está disponible en $<$ https: $/ /$ rmc.library. cornell.edu/gettysburg/good_cause/transcript.htm $>(23 / 01 / 2021)$. equal», - esculpidas, como versículos bíblicos, en la memoria colectiva de generaciones de americanos - para que actuaran, a modo de conjuro, contra una pesadilla antisemita y fascista que todavía se mostraba reacio a admitir. ${ }^{42}$

Uno de los grandes cambios que se producían en el guion cinematográfico de $E l$ hombre en el castillo con respecto a la novela original tenía que ver con el objeto de deseo por parte de las potencias del Eje. Si en la obra de Philip K. Dick se trataba de un libro titulado La langosta se ha posado, en la serie producida por Ridley Scott este codiciado volumen se convertía en un conjunto de cortometrajes que circulaban, de manera clandestina, ofreciendo una historia alternativa al curso de la historia donde los Aliados eran quienes realmente habían resultado vencedores en la Segunda Guerra Mundial. Esta trascendental modificación permitía a los personajes viajar a mundos paralelos al sugerir la serie de Amazon que aquellas cajas que contenían rollos de película de $8 \mathrm{~mm}$ eran traídas por viajeros intertemporales pertenecientes a la Resistencia.

En el episodio cuarto de la última temporada («Happy Trails»), la protagonista, Juliana Crain, se dirigía en coche hacia el National Mall. La radio daba la noticia del nombramiento de Lyndon B. Johnson como presidente de los Estados Unidos después del asesinato de Kennedy. Tras una rápida visita a la estatua de otro de los presidentes asesinados en la historia del país, instante que cobraría una fuerte significación simbólica en la siguiente secuencia, Juliana se sentaba en las escaleras del Memorial a Lincoln. De frente al Monumento a Washington, conseguía, a través de la meditación taoísta, transportarse al mundo paralelo en el que Japón y Alemania habían ganado la guerra.

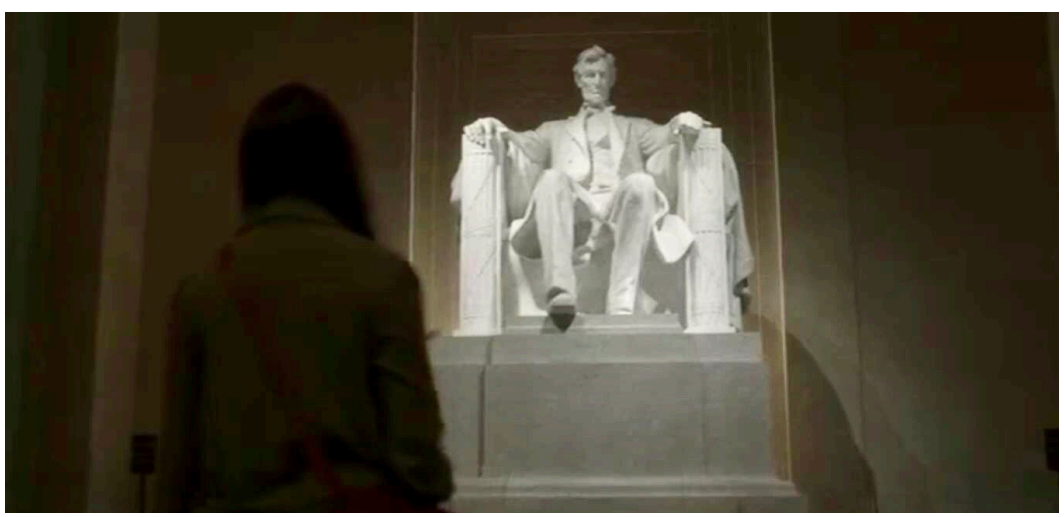

Izquierda, Juliana Crain en el interior del Memorial a Lincoln. Fotograma del episodio 4 («Happy Trails») de la cuarta temporada de El hombre en el castillo. Abajo, meditación taoísta frente al Monumento a Washington. Fotograma del episodio 4 («Happy Trails») de la cuarta temporada de El hombre en el castillo.

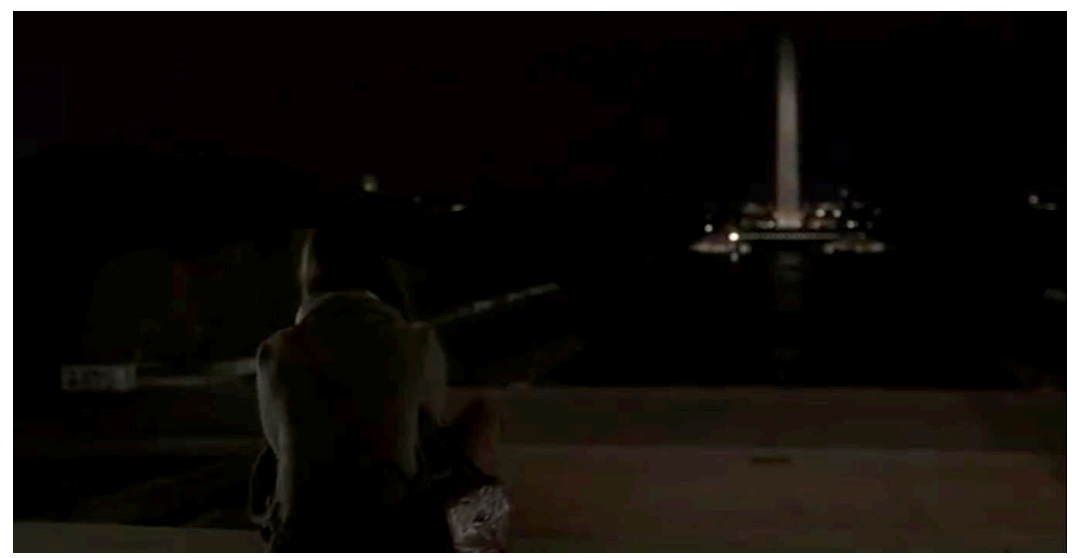


El espectador observaba, al mismo tiempo que Juliana abría los ojos, que en el Nuevo Orden fascista de los años sesenta el National Mall había quedado arrasado y se había convertido en una zona prohibida que las autoridades alemanas denominaban «The District of Contamination». Como testigo y testimonio arquitectónicos de la humillación infringida sobre la democracia americana pero también acogiéndose a la Ruinenwerttheorie de Speer y Hitler, los nazis habían decidido dejar, tal y como quedaron después de la guerra, los famosos monumentos y memoriales que caracterizaban a la antigua capital de los Estados Unidos: así se podía contemplar, por ejemplo, la estatua de Lincoln decapitada o una vista aérea del Capitolio destruido. ${ }^{43}$
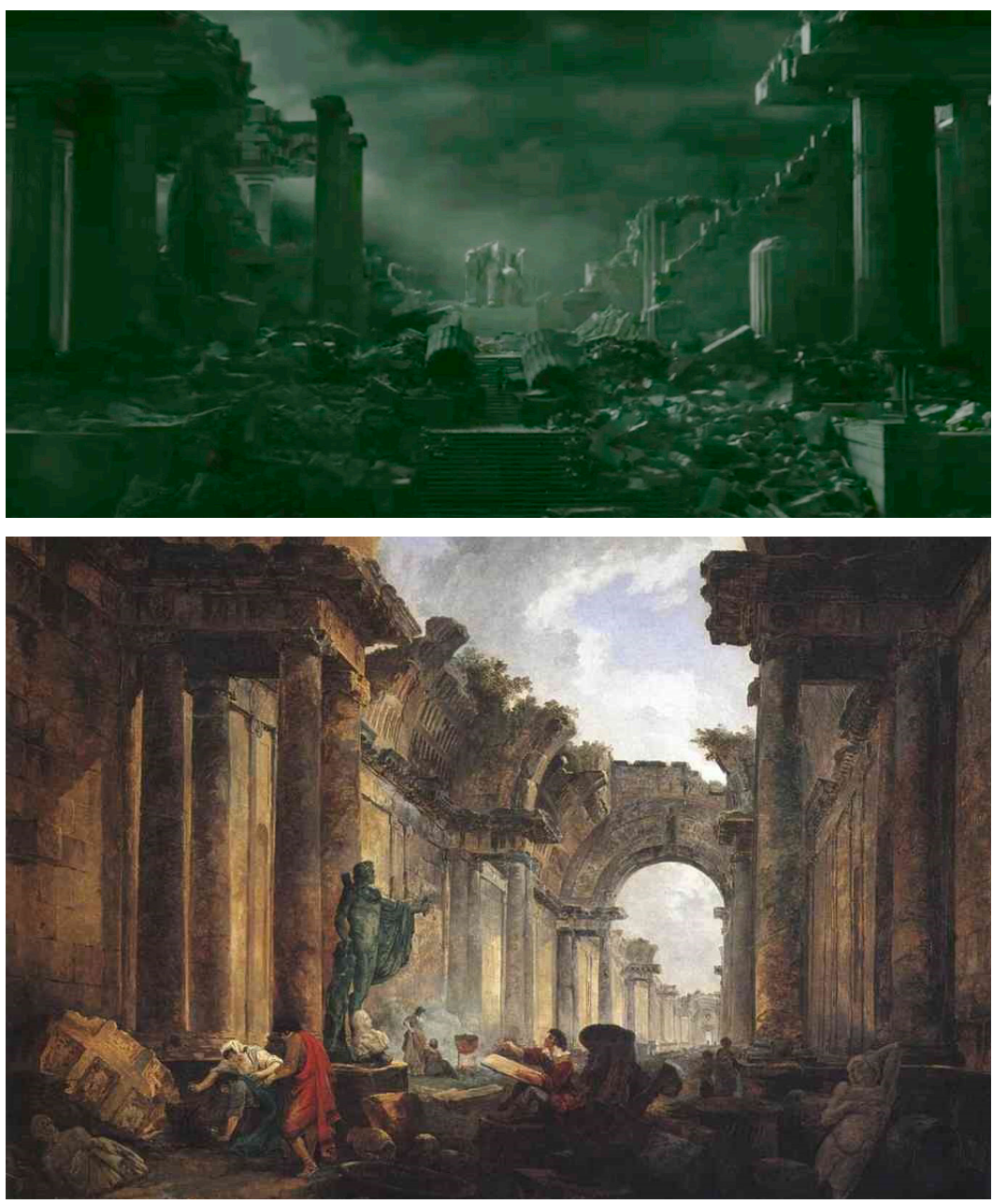

Arriba, La destrucción de la democracia americana. Fotograma del episodio 4 («Happy Trails») de la cuarta temporada de El hombre en el castillo. Abajo, Vista imaginaria de la Gran Galería del Louvre en ruinas (1796, Hubert Robert).

Juliana deambulará, por tanto, por un escenario dantesco y ruinoso como si se tratara de un personaje en el interior de un lienzo de Hubert Robert donde las ruinas clásicas, invadidas por la vegetación, servían de marco a la vida dieciochesca.

La diferencia con el pintor francés estribaba en que en el centro histórico de
[43] Por lo que se refería a Nueva York, los nazis demolían otro de los grandes iconos arquitectónicos del ideario americano como era la Estatua de la Libertad (último episodio de la tercera temporada: «Jahr Null») para sustituirla por un conjunto escultórico característico del colosalismo de Josef Thorak o Arno Breker (episodio siete de la cuarta temporada: «No Masters But Ourselves»). 
[44] «[...] y ese gobierno del pueblo, por el pueblo, para el pueblo, no perecerá de la tierra» (La traducción es nuestra).

[45] «In this temple, as in the hearts of the people for whom he saved the Union, the memory of Abraham Lincoln is enshrined forever» («En este templo, como en los corazones de las personas para quienes salvó la Unión, el recuerdo de Abraham Lincoln está consagrado para siempre») (La traducción es nuestra).

[46] Durante el primer año (entre febrero y septiembre) del gobierno de Trump la estatua de Lincoln sufrió tres actos vandálicos: véanse $<$ https://www. nbcwashington.com/news/local/ world-war-ii-memorial-lincoln-memorial-washington-monument-vandalized-in-dc/36658/> (23/01/2021); <https://www. nbcwashington.com/news/local/ lincoln-memorial-vandalized-with-red-spray-paint/24880/> (23/01/2021); <https://www. washingtonpost.com/local/public-safety/man-arrested-after-vandalizing-lincoln-memorial-with-penny-police-say/2017/09/19/0 84a7e54-9d5e-11e7-84fb-b48314 36e807_story.html > (23/01/2021).

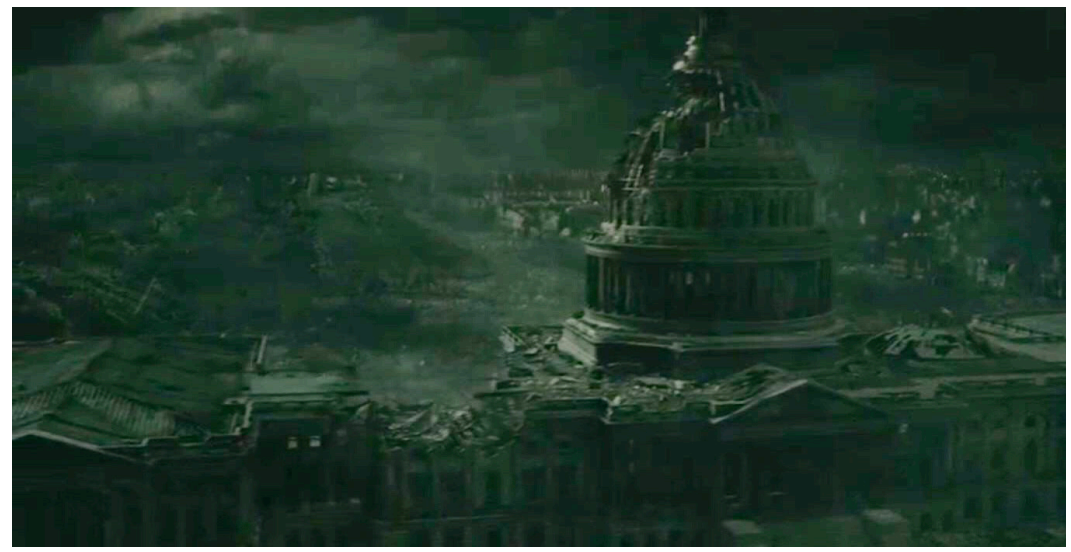

Plano aéreo del National Mall con el Capitolio bombardeado. Fotograma del episodio 4 («Happy Trails») de la cuarta temporada de El hombre en el castillo.

Washington no existía la vida: solo perros callejeros y un par de rebeldes que se atrevían a desafiar al gobierno de ocupación dibujando el símbolo de la Resistencia o escribiendo, sobre las paredes de lo que había sido en su día el Memorial a Lincoln, la última frase del Discurso de Gettysburg: «[...] and that government of the people, by the people, for the people, shall not perish from the earth». ${ }^{44}$

«Household» era uno de los pocos episodios de El cuento de la criada (sexto de la tercera temporada) en el que a June se le permitía salir de su enclaustramiento en Gilead. El motivo estaba más que justificado para el matrimonio Waterford. Su criada debía acompañarlos a la nueva Washington con la misión de meter presión internacional y, de este modo, conseguir que el gobierno canadiense repatriara a su hija Nicole. En este viaje no estarían solos. Todas las criadas de Gilead apoyarían aquella puesta en escena propagandística para que el espectáculo filmado fuera más poderoso y efectista ante los medios de comunicación.

La secuencia que culminaba el episodio tenía dos partes claramente diferenciadas: una interior y privada rodada en la sala central del Memorial a Lincoln y otra, exterior, a plena luz del día, y de carácter ritualista, que tenía lugar al pie de las escaleras del monumento frente al Reflecting Pool. En la primera, una June, literalmente amordazada con el nuevo accesorio represor que le había dado anteriormente la Tía Lydia para ocultarle la boca, penetraba en la sala. El contraste entre aquella esclava sexual de la República de Gilead, a la que ahora se le incapacitaba para poder hablar, y la estatua del presidente que había abolido la esclavitud en los Estados Unidos no podía ser más estremecedor y paradójico. Además, como hemos observado en el episodio de El hombre en el castillo, la estatua de Lincoln aparecía, una vez más, decapitada y con la inscripción, que se encuentra detrás de su efigie, borrada de la pared. ${ }^{45}$

Tras observar el vandalismo gubernamental ejecutado contra aquella escultura por todo lo que representaba, su primer gesto simbólico, y de rebeldía, era despojarse de aquella mordaza que la anulaba como ser humano pero también como ciudadano de un país que había sido libre gracias a personajes como Lincoln. ${ }^{46} \mathrm{La}$ antítesis entre el antes y el después de los Estados Unidos como nación, se materializaba en la confrontación dialéctica entre June y Serena Waterford dentro del mismo escenario alegórico como testigo: un duelo ideológico que, desde la Guerra Civil americana, permanece en una sociedad norteamericana cada vez más polarizada desde que Donald Trump se hiciera con el poder.

$\mathrm{Su}$ reacción posterior, mezclada de rabia, tristeza e impotencia, indicaba bien 

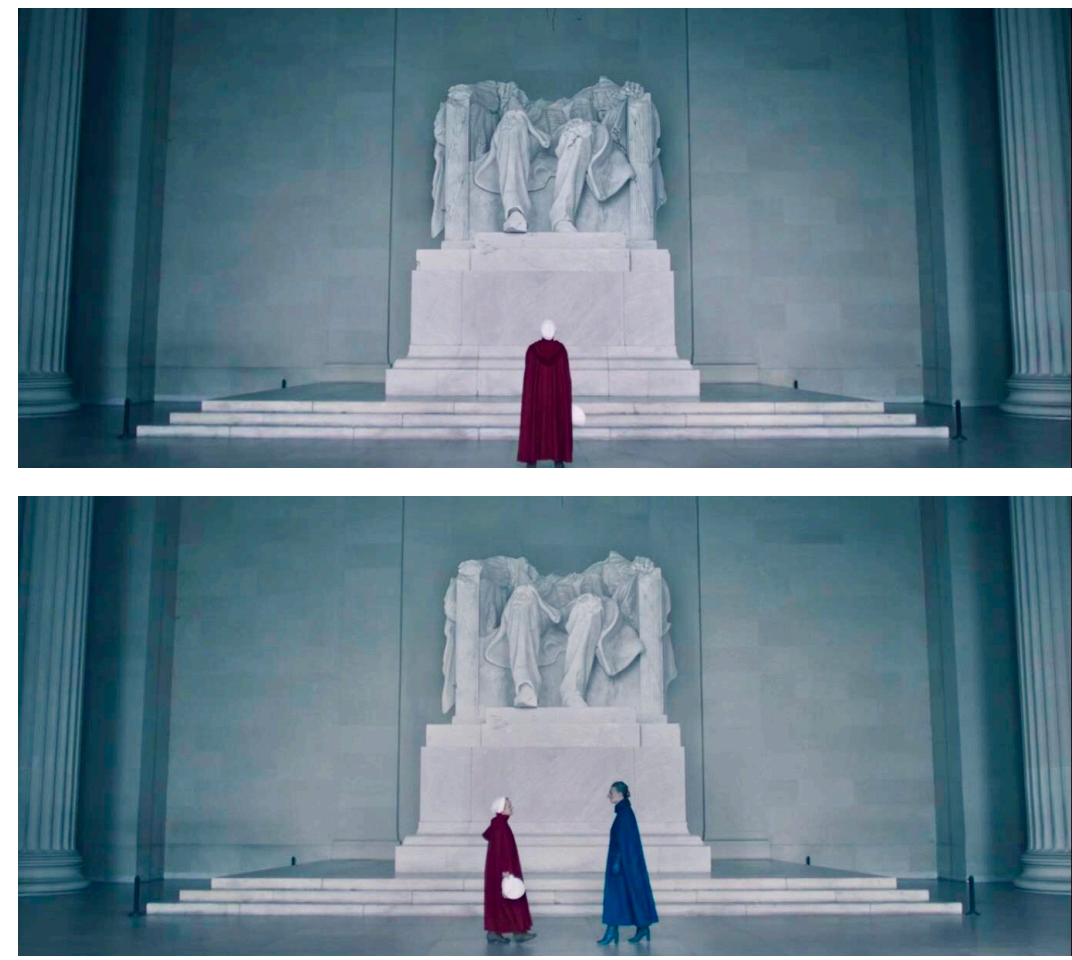

Arriba, June ante la estatua de Lincoln, decapitada por la República de Gilead. Fotograma del episodio 6 («Household») de la tercera temporada de El cuento de la criada. Abajo, las dos Américas, frente a frente. Fotograma del episodio 6 («Household») de la tercera temporada de El cuento de la criada.

a las claras que era la primera vez que visitaba la nueva capital de Gilead después del golpe de Estado perpetrado por los Hijos de Jacob, responsables de liquidar el Congreso. ${ }^{47}$ Antes de abandonar el recinto interior de lo que había sido en su día el Memorial a Lincoln, June se aproximaba a la estatua y, como una ferviente creyente de una religión proscrita, lloraba desconsoladamente al pie del que había sido definido por el narrador de La conjura contra América como «el rostro de Dios y el de América».

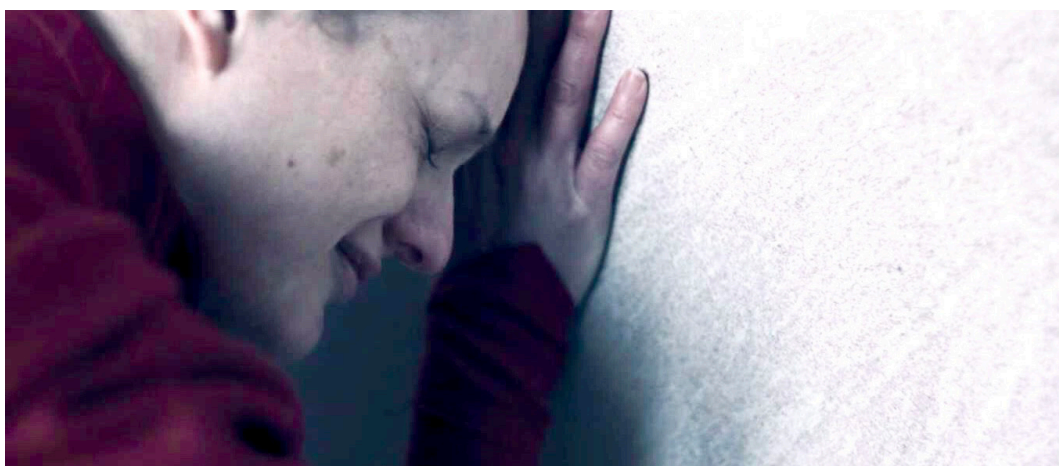

June, llorando al pie de la estatua de Lincoln. Fotograma del episodio 6 («Household») de la tercera temporada de El cuento de la criada.
[47] Margaret Atwood, El cuento de la criada (Barcelona, Ediciones Salamandra, 2017), p. 12 y Margaret Atwood, Los testamentos (Barcelona, Ediciones Salamandra, edición para Kindle, 2019), loc. 924. 
En la novela de Philip Roth, la familia judía, después de visitar el Memorial, se topaba de frente con el alto monolito del Monumento a Washington, a unos ochocientos metros de distancia, y con el estanque reflectante, «el panorama más bello que había visto jamás, un paraíso patriótico, el Jardín del Edén americano extendido ante nosotros»» ${ }^{48}$ Herman pedía a sus hijos, otra vez, que echaran un último vistazo a Abraham Lincoln antes de regresar al hotel. En el episodio de la serie de El cuento de la criada June adoptaba una conducta muy similar. Mientras se encaminaba pausadamente hacia el exterior, volvería la cabeza hacia la estatua decapitada para contemplar, por última vez, cómo habían aniquilado los valores en los que se había fundado el país: unos ideales y unos derechos conquistados en los que Herman Levin no dejaría de insistir durante la visita a Washington ante la alargada sombra del fascismo que se estaba proyectando sobre los Estados Unidos. Los temores de los Levin a que fueran expulsados del «paraíso patriótico» se habían cumplido para ciudadanos como June con la irrupción de aquel Nuevo Estado. A aquel «Jardín del Edén americano» le había sido usurpado su propio significado ético-ideológico y lo que se extendía ante la mirada de June ya no era el National Mall como ella lo había conocido: la cúpula del Capitolio había desaparecido del skyline de la antigua capital y, sobre todo, una colosal cruz ocupaba el lugar en el que se había erigido el obelisco de Washington.

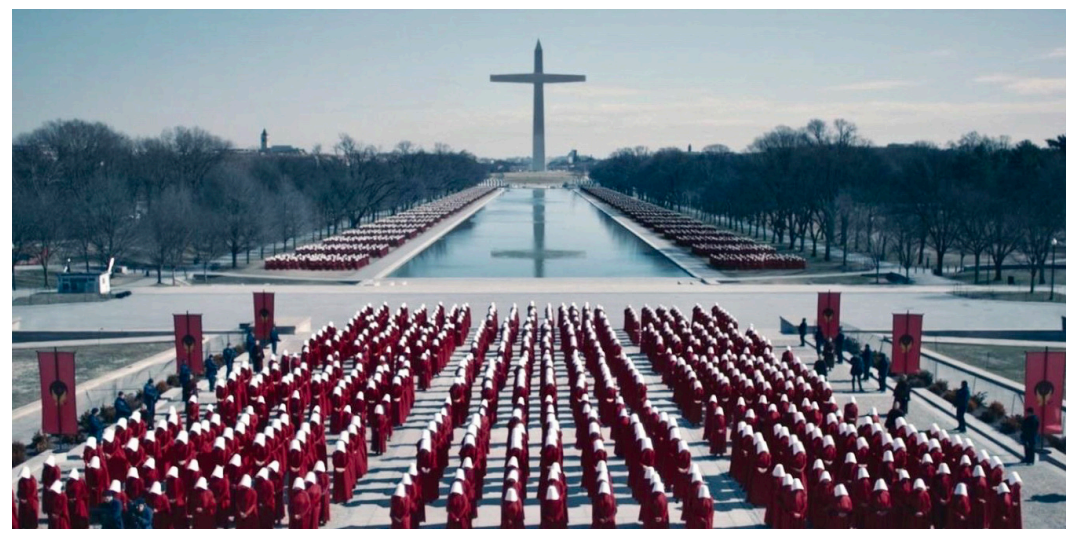

La gran Cruz del régimen teocrático de Gilead dominando toda la explanada del National Mall. Fotograma del episodio 6 («Household») de la tercera temporada de El cuento de la criada.

Aquella cruz constituía la muestra fehaciente de la visibilidad ideológica de aquel gobierno teocrático, fundamentalista y puritano, pero donde «el catolicismo se considera herético y poco menos que vudú». ${ }^{49}$ Asimismo, aquel símbolo de la redención cristiana poseía para la jerarquía de la República de Gilead otros propósitos. Representaba la definitiva ocupación del espacio público y el uso de la arquitectura como creación, primero, de un recinto mágico y, segundo, como mecanismo de control intimidatorio (debido a sus dimensiones megalómanas) y de represión preventiva sobre la población — y contra toda disidencia política - para movilizarla, cohesionarla y homogeneizarla a través de numerosos actos públicos. Estos, a su vez, facilitarían el proceso de desindividualización y desmemorización en cuanto a los antiguos re-

[48] Philip Roth, La conjura contra América, loc. 1189.

[49] Margaret Atwood, Los testamentos, loc. 516. ferentes culturales, ideológicos y políticos del sistema anterior. En el caso concreto de la ritualización que tenía lugar al pie de la escalinata que conducía al Memorial a Lincoln, la estética aludía directamente a los Congresos de Núremberg filmados por Leni Riefenstahl en El triunfo de la voluntad (Triumph des Willens, 1935). 
Ahora, en lugar de los cuerpos de las SS y SA que escuchaban el discurso de Hitler en el Luitpoldarena, se alineaba, en formación militar, el rojo masificado de las criadas que habían acudido a Washington para participar en aquella ceremonia tan fundamental para Gilead. En una sociedad donde el catolicismo había desaparecido como religión de Estado y sus sacerdotes eran ejecutados, la religión, sin embargo, continuaba siendo el soporte ideológico principal para dominar a las masas.

Al igual que el nacionalsocialismo había convertido al Führer en el Sumo Sacerdote de la nueva religión del Tercer Reich, el comandante Fred Waterford oficiaba, en compañía de su esposa Serena, aquella misa al aire libre como director de la puesta en escena de toda la escenografía

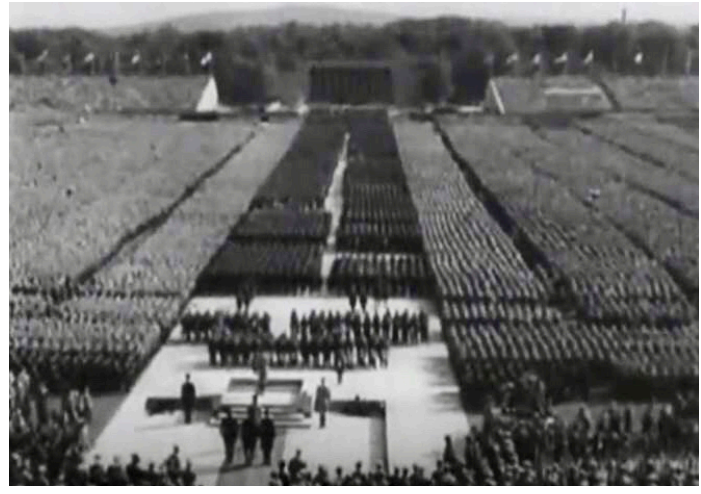

El Congreso de Núremberg de 1934. Fotograma de El triunfo de la voluntad (Leni Riefenstahl, 1935) desplegada por la propaganda del régimen. La liturgia fastuosa se enmarcaba, pues, en aquel espacio totalitario, sagrado e hipnótico, en el que se producía la definitiva fusión entre el líder carismático y los miembros de la comunidad nacional de Gilead. No sería ninguna casualidad que la última mirada de June se posara, de nuevo, en aquella cruz que, amenazadoramente reflejada sobre la pupila de su ojo, le haría recordar, para siempre, que un día ella también fue una ciudadana libre... en unos Estados Unidos libres.
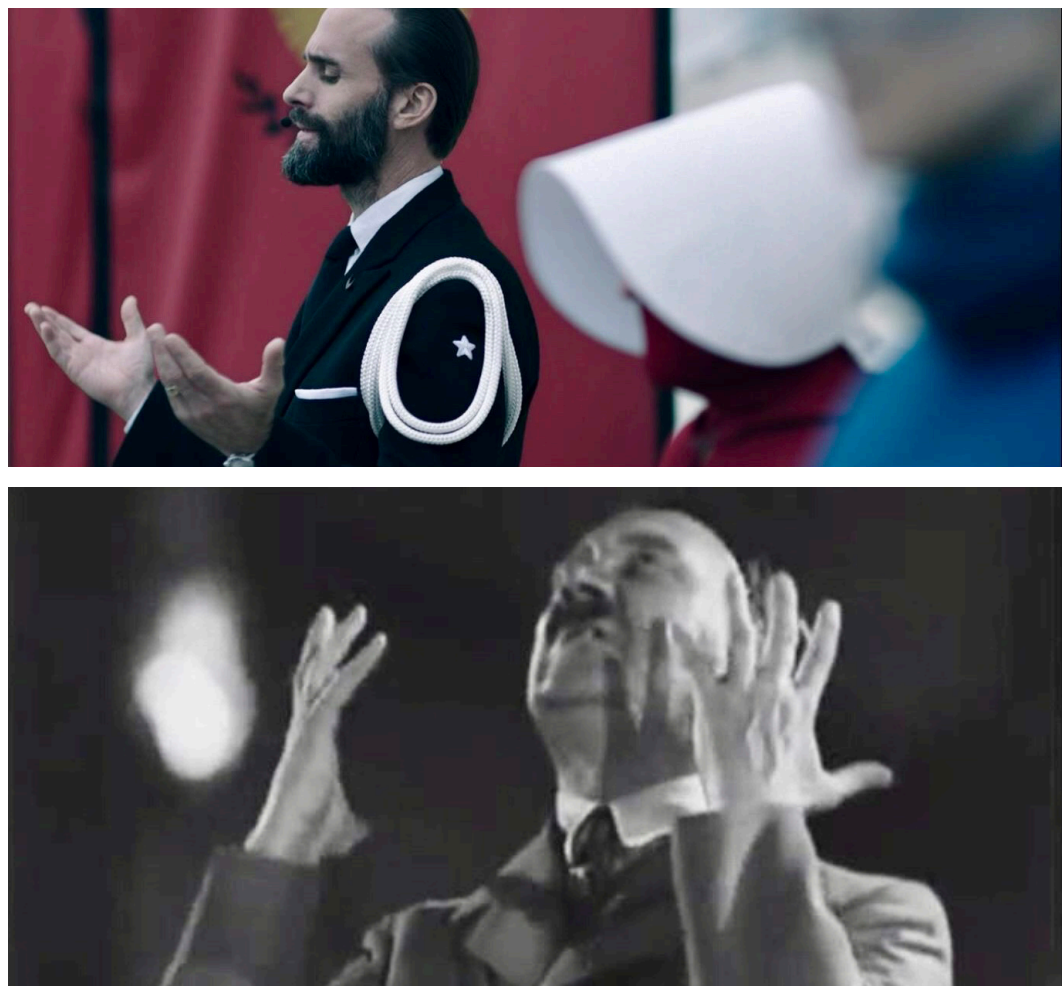

Arriba, el comandante Fred Waterford preside una celebración litúrgica en el nuevo régimen. Fotograma del episodio 6 ("Household») de la tercera temporada de El cuento de la criada. Abajo, el éxtasis de Adolf Hitler frente a sus camaradas del Partido nazi. Fotograma de El triunfo de la voluntad (Leni Riefenstahl, 1935) 


\section{Conclusiones}

Con este artículo se ha pretendido contextualizar la visión desesperanzadora y profundamente pesimista de tres series de éxito tales como El hombre en el castillo, El cuento de la criada y La conjura contra América en lo que se refiere a la situación política actual de los Estados Unidos. A través del género de la distopía o la ucronía, estas series han (re)adaptado el material literario original para adecuarlo a un periodo muy específico del país y con un presidente, Donald Trump, que ha dañado la imagen de una de las democracias más antiguas del mundo negándose a aceptar la victoria de su contrincante en las elecciones de noviembre de 2020 y amenazando con impugnarlas ante la Corte Suprema: una legislatura que ha tenido, como colofón, en la ocupación —ya no simbólica ni ficticia — del Capitolio por parte de sus seguidores un final solo al alcance de la imaginación de escritores y guionistas.

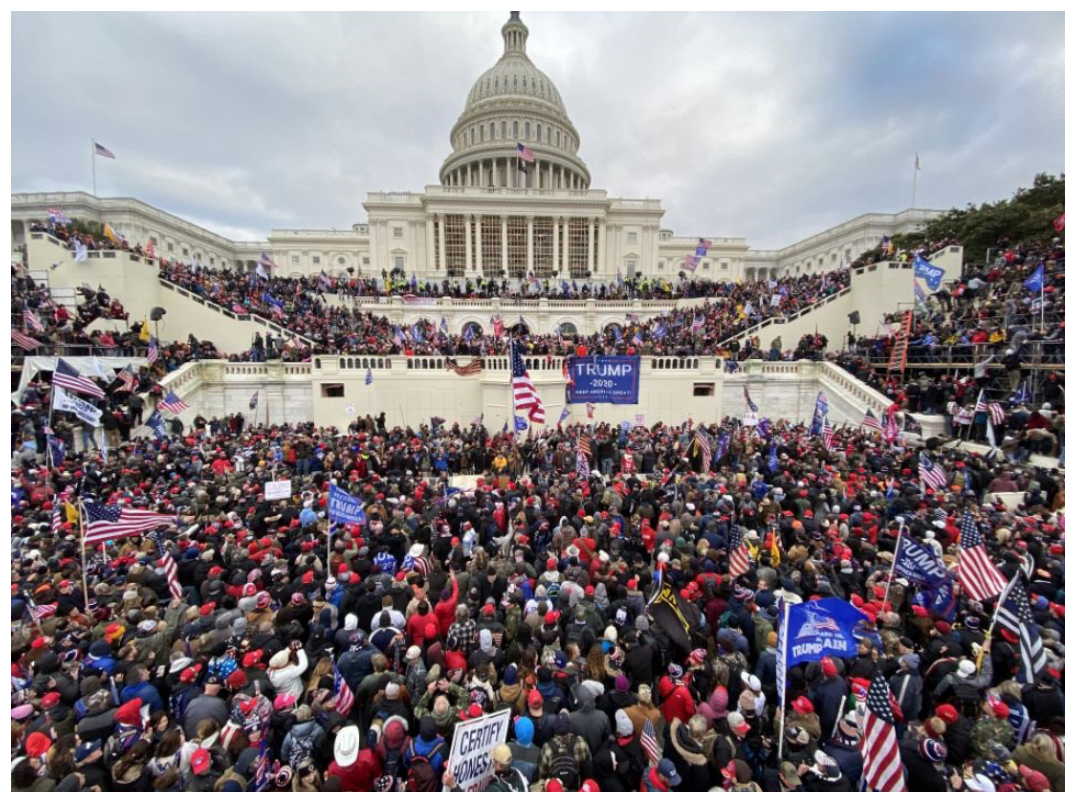

Seguidores de Donald Trump ocupan el 6 de enero de 2021 todo el recinto del Capitolio en la capital norteamericana.

Sin entrar en el debate acalorado que se estableció en la prensa especializada sobre la idoneidad, o no, de establecer comparaciones entre la administración Trump y los regímenes teocráticos y autoritarios que aparecían representados en las series, es indudable que estas, al igual que hiciera Sinclair Lewis durante los años treinta con su novela Eso no puede pasar aquí, están alertando de una coyuntura de crisis económica de la que se suelen retroalimentar históricamente los populismos, tanto de derechas como de izquierdas, y la demagogia de salvadores e iluminados. En nuestro caso, hemos querido poner el foco de atención sobre la presencia física de la capital de los Estados Unidos en tres episodios muy concretos que, debido al significado que atesora la ciudad y sus emblemáticos monumentos como espacio propagandístico de la democracia americana, ejemplifica, de alguna forma, ese conflictivo diálogo entre el presente y un futuro incierto. Será a partir, por lo tanto, de la exposición ficcional de la destrucción y ocupación ideológica del espacio público de Washington, D.C. cuando se 
hagan más extensibles los miedos, las dudas y las incertidumbres que, desde siempre, ha sentido parte de la industria cinematográfica más progresista hacia cualquier atisbo de renacimiento o auge de la América más profunda.

Con todo, creemos que no solo existen nubarrones en el horizonte. La luz hacia la esperanza la ponía el último episodio de La conjura contra América. Tras la misteriosa desaparición del presidente Charles Lindbergh, unas nuevas elecciones convocaban al electorado para que acudiera a las urnas en noviembre de 1942. En aquella historia sobre las vicisitudes de una familia judía ante el ascenso del fascismo en su país se escucharía como banda sonora para tal señalado día, y no por azar, la canción que interpretaba Frank Sinatra en el cortometraje del mismo nombre The House I Live In (Mervyn LeRoy, 1945): una producción de la RKO contra la intolerancia antisemita en la que «la Voz» se preguntaba «What is America to me?». Y eso es lo que muy probablemente se habrán interpelado muchos ciudadanos americanos al votar a Joe Biden después de cuatro años de trumpismo.

\section{BIBLIOGRAFÍA}

Abensour, Miguel, «De la compacidad» (Revista de Estudios Sociales, n. ${ }^{\circ} 35$, abril de 2010). Disponible en: https://journals.openedition.org/revestudsoc/14603

AdAm, Peter, El arte del Tercer Reich (Barcelona, Tusquets, 1992).

Altares, Guillermo, «La llegada de Trump convierte 1984 en superventas en EEUU» (El País, 27 de enero de 2017). Disponible en: https://elpais.com/cultura/ 2017/01/26/actualidad/1485423697_413624.html

ARENDT, Hannah, La condición humana (Barcelona, Paidós, 1998).

Arteaga, Nelson, «La historia como realidad y ficción: los distintos mundos de $E l$ hombre en el castillo» (Norteamérica, vol. 13, n. ${ }^{\circ} 2,2018$ ), pp. 299-318.

ATwOoD, Margaret, El cuento de la criada (Barcelona, Ediciones Salamandra, 2017).

—, Los testamentos (Barcelona, Ediciones Salamandra, edición para Kindle, 2019).

BARCeló, Miquel, «Los temas de la ciencia ficción» (Revista de literatura, n. ${ }^{\circ}$ 205, 2004), pp. 57-66. Disponible en: http://www.centrocp.com/los-temas-de-laciencia-ficcion/

Blanco, Silvia, Sahuquillo, María y Vidal, Macarena, «Democracia en cuarentena por coronavirus» (El País, 31 de marzo de 2020). Disponible en: https://elpais. com/internacional/2020-03-30/democracia-en-cuarentena-por-coronavirus.html

Box, Zira, «El cuerpo de la nación. Arquitectura, urbanismo y capitalidad en el primer franquismo» (Revista de Estudios Políticos, n. ${ }^{\circ}$ 155, 2012), pp. 151-181.

Burston, Daniel, «It Can't Happen Here: Trump, Authoritarianism and American Politics» (Psychotherapy and Politics International, n. ${ }^{\circ}$ 205, 2017), pp. 1-9.

Cascajosa Virino, Concepción Carmen, «Procesos de hipertextualidad en la ficción televisiva norteamericana» (Área abierta, n. ${ }^{\circ}$ 5, 2003), pp. 1-12.

—, «El espejo deformado: Una propuesta de análisis del reciclaje en la ficción audiovisual norteamericana» (Revista Latina de Comunicación Social, n. ${ }^{\circ}$ 61, 2006).

—, «Los turbios reflejos de la utopía en la ficción televisiva serial norteamericana» (Paradigma: revista universitaria de cultura, n. $\left.^{\circ} 19,2016\right)$, pp. 30-33. 
Снарочтот, Johann, El nacionalsocialismo y la antigüedad (Madrid, Abada Editores, 2013).

CnN, «Asesora de Trump: Casa Blanca citó 'hechos alternativos' sobre asistencia a toma de posesión» (CNN, 22 de enero de 2017). Disponible en: https://cnn.it/2IJsLh3

CRISPIN, Jessa, «The Handmaid's Tale is just like Trump's America? Not so fast» (New Yorker, 2 de mayo de 2017). Disponible en: https://www.theguardian.com/com mentisfree/2017/may/02/handmaids-tale-donald-trump-america

Da costa, Marco, Hollywood contra Hitler (Madrid, Notorious Ediciones, 2018).

Delgado, Manuel, El espacio público como ideología (Madrid, Catarata, 2011).

Edman, Timucin, Gözen, Hacer y Peaci, Davut, «The Man in the High Castle: An Awry Reality Through Post-Truth» (Interactions, vol. 29, n. ${ }^{\circ}$ 1-2, 2020), pp. 77-100.

Fallon, Kevin, «The Man in the High Castle: Creator Frank Spotnitz on Making Amazon's Hit Drama» (Daily Beast, 27 de noviembre de 2015). Disponible en: https://www.thedailybeast.com/the-man-in-the-high-castle-creator-frank-spotnitzon-making-amazons-hit-drama

FAus, Joan, «El triunfo de Donald Trump galvaniza a la derecha racista de Estados Unidos» (El País, 22 de noviembre de 2016). Disponible en: https://elpais.com/ internacional/2016/11/21/estados_unidos/1479765598_617726.html

FINK, Moritz, «Why America Fought: Post-Postmodernism in Amazon's The Man in the High Castle» (SPIEL: Journal of Media Culture, vol. 2, n. ${ }^{\circ}$ 2, 2016), pp. 127-146.

Harris, Robert, Patria (Barcelona, Random House, edición para Kindle, 2011).

Jones, Sarah, «The Handmaid's Tale Is a Warning to Conservative Women» (The New Republic, 20 de abril de 2017). Disponible en: https://newrepublic.com/ article/141674/handmaids-tale-hulu-warning-conservative-women

KAY, Barbara, «The problem with The Handmaid's Tale is that it's not a believable dystopia. It's sci-fi» (National Post, 2 de mayo de 2017). Disponible en: https:// nationalpost.com/opinion/barbara-kay-the-problem-with-handmaids-tale-isthat-its-not-a-believable-dystopia-its-sci-fi

Kellner, Douglas y Ryan, Michael, Camera Politica: The Politics and Ideology of Contemporary Hollywood Film (Bloomington, Indiana University Press, 1990).

Kopleck, Maik, Berlin, 1933-1945 (Berlín, Christoph Links, 2005).

—, München, 1933-1945 (Berlín, Christoph Links, 2006).

—, Obersalzberg, 1933-1945 (Berlín, Christoph Links, 2007).

Lewis, Sinclair, Eso no puede pasar aquí (Madrid, A. Machado Libros, edición para Kindle, 2012).

Lincoln, Abraham, Gettysburg Adress, 19 de noviembre de 1863. Disponible en: https://rmc.library.cornell.edu/gettysburg/good_cause/transcript.htm

Malmgren, Carl D., «Against Genre/Theory: The State of Science Fiction Criticism» (Poetics Today, vol. 12, n. ${ }^{\circ} 1,1991$ ), pp. 125-144. Disponible en:https://scholarworks. uno.edu/cgi/viewcontent.cgi?article $=1048 \&$ context=engl_facpubs

Mead, Rebeca, «The Prophet of Dystopia» (New Yorker, 17 de abril de 2017). Disponible en: https://www.newyorker.com/magazine/2017/04/17/mar-garetatwood-the-prophet-of-dystopia

Michaud, Éric, La estética nazi. Un arte de la eternidad (Buenos Aires, AH, 2009).

Moreno Serrano, Fernando Ángel, Teoría de la literatura de ciencia ficción: Poética y retórica de lo prospectivo (Vitoria, Portal Ediciones, 2010).

Neelakantan, Gurumurthy, «Philip Roth's Nostalgia for the Yiddishkayt and the New Deal Idealisms in The Plot Against America» (Philip Roth Studies, vol. 4, 
n. $\left.{ }^{\circ} 2,2008\right)$, pp. $125-136$.

RAMÍREZ NÁRDIZ, Alfredo, «Aproximación al pensamiento político de Donald Trump: ¿es el presidente de Estados Unidos populista?» (Revista Española de Ciencia Política, n. ${ }^{\circ}$ 52, 2020), pp. 59-83.

Rотн, Philip, La conjura contra América (Barcelona, Random House, edición para Kindle, 2011).

RuEDA, Javier, «Reescrituras de la historia americana» (Caimán. Cuadernos de cine, n. ${ }^{\circ} 92$, abril de 2020), pp. 40-43.

Sala Rose, Rosa, Diccionario crítico de mitos y símbolos del nazismo (Barcelona, Acantilado, 2003).

Schmidt, Alexander y Urban, Markus, Terreno de las convenciones del Partido del Reich en Núremberg (Nuremberg, Geschichte Für Alle, 2007).

ShIRvani, Majid, «Deconstructing Roth's The Plot Against America: The Making of the President Donald Trump», en C. Ignatescu, A. Sandu y T. Ciulei (eds.), Re thinking Social Action. Core Values in Practice (Suceava, Lumen Proceedings, 2017), pp. 808-819.

Soвснаск, Vivian, Screening Space: The American Science Fiction Film (New Brunswick, Rutgers University Press, 1997).

SPEer, Albert, Memorias (Barcelona, Acantilado, 2001).

Stern, Michael, «Making Culture into Nature», en Annette Kuhn (ed.), Alien Zone: Cultural Theory and Contemporary Science Fiction Cinema (Londres, Verso, 1990), pp. 66-72.

Suvin, Darko, «On the Poetics of the Science Fiction Genre» (College English, vol. 34, n. ${ }^{\circ}$ 3, Dec. 1972), pp. 372-382.

—, «Radical Rhapsody and Romantic Recoil in the Age of Anticipation: A Chapter in the History of SF» (Science Fiction Studies, vol. 1, n. ${ }^{\circ} 4$, Fall 1974). Disponible en:https://www.depauw.edu/sfs/backissues/4/suvin4art.htm

-, Metamorfosis de la ciencia ficción. Sobre la poética y la historia de un género literario (Ciudad de México, Fondo de Cultura Económica, 1984).

Telotte, J. P., El cine de ciencia ficción (Madrid, Cambridge University Press, 2002).

Tilly, Charles, Democracia (Madrid, Akal, 2010).

Trevor-Roper, Hugh (ed.), Las conversaciones privadas de Hitler (Barcelona, Crítica, 2004).

Urbain, Thomas, "La conjura contra América, un paralelismo audaz con el ascenso de Trump» (Arcadia, 16 de marzo de 2020). Disponible en: https://www. revistaarcadia.com/television/articulo/la-conjura-contra-america-de-hboparalelismo-audaz-con-el-ascenso-de-trump/81171

Vials, Christopher, «What Can Happen Here?: Philip Roth, Sinclair Lewis, and the Lessons of Fascism in the American Liberal Imagination» (Philip Roth Studies, vol. 7, n. $\left.{ }^{\circ} 1,2011\right)$, pp. 9-26.

Wright, Judith Hess, «Genre Films and the Status Quo», en Barry Keith Grant (ed.), Film Genre Reader IV (Austin, University of Texas Press, 2012), pp. 60-68.

Recibido: 31 de mayo de 2020

Aceptado para revisión por pares: 7 de septiembre de 2020

Aceptado para publicación: 16 de enero de 2021 